\title{
DÜBLIN
}

Technological University Dublin ARROW@TU Dublin

Articles

Crest: Centre for Research in Engineering

Surface Technology

2018

\section{Self-Healing Asphalt Review: From Idea to Practice}

S. Xu

Delft University of Technology

Alvaro García

University of Nottingham

Junfeng Su

Tianjin Polytechnic University

See next page for additional authors

Follow this and additional works at: https://arrow.tudublin.ie/cenresart

Part of the Engineering Commons

\section{Recommended Citation}

Xu, S. et al. (2018) Self-Healing Asphalt Review: From Idea to Practice, Adv. Mater. Interfaces 2018, 5, 1800536 DOI: $10.1002 /$ admi.201800536

This Article is brought to you for free and open access by the Crest: Centre for Research in Engineering Surface Technology at ARROW@TU Dublin. It has been accepted for inclusion in Articles by an authorized administrator of ARROW@TU Dublin. For more information, please contact arrow.admin@tudublin.ie, aisling.coyne@tudublin.ie,gerard.connolly@tudublin.ie.

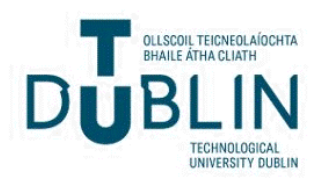




\section{Authors}

S. Xu, Alvaro García, Junfeng Su, Quantao Liu, Amir Tabakovic, and Erik Schlangen

This article is available at ARROW@TU Dublin: https://arrow.tudublin.ie/cenresart/69 


\section{Delft University of Technology}

\section{Self-Healing Asphalt Review \\ From Idea to Practice}

Xu, Shi; García, Alvaro; Su, Junfeng; Liu, Quantao; Tabakovic, Amir; Schlangen, E.

DOI

10.1002/admi.201800536

Publication date

2018

Document Version

Final published version

Published in

Advanced Materials Interfaces

\section{Citation (APA)}

Xu, S., García, A., Su, J., Liu, Q., Tabaković, A., \& Schlangen, E. (2018). Self-Healing Asphalt Review: From Idea to Practice. Advanced Materials Interfaces, 5(17), 1-21. [1800536].

https://doi.org/10.1002/admi.201800536

\section{Important note}

To cite this publication, please use the final published version (if applicable).

Please check the document version above.

\section{Copyright}

Other than for strictly personal use, it is not permitted to download, forward or distribute the text or part of it, without the consent of the author(s) and/or copyright holder(s), unless the work is under an open content license such as Creative Commons.

\section{Takedown policy}

Please contact us and provide details if you believe this document breaches copyrights.

We will remove access to the work immediately and investigate your claim. 
Green Open Access added to TU Delft Institutional Repository 'You share, we take care!' - Taverne project

\section{https://www.openaccess.nl/en/you-share-we-take-care}

Otherwise as indicated in the copyright section: the publisher is the copyright holder of this work and the author uses the Dutch legislation to make this work public. 


\title{
Self-Healing Asphalt Review: From Idea to Practice
}

\author{
Shi Xu, Alvaro García, Junfeng Su, Quantao Liu, Amir Tabaković, and Erik Schlangen**
}

In recent decades, researchers have revealed the great healing potential of asphalt and proposed various novel methods to inspire and improve the selfhealing capacity of asphalt aimed to prolong the service life of asphalt pavement. In this review, up to date research progresses in induction healing and embedded rejuvenator encapsulation are presented, respectively. Meanwhile, the trial section applications of induction healing and capsule healing are highlighted, which show promising results. Finally, some recommendations for the future development of self-healing asphalt are proposed. to be cohesive when occurring in the bitumen or mastic and to be adhesive when occurring at the bitumen-aggregate interface.

For the explanation of the healing mechanism in bitumen, Lytton and coworkers ${ }^{[3]}$ concluded that healing is the recovery of material properties and diminishing of cracking of bitumen and asphalt mixes. It can be explained in two ways:

\section{i) Physicochemical Way}

\section{Introduction}

With the advantages of cost efficiency, noise reduction, and comfort driving experience, asphalt is widely used as a binding material in pavement engineering. However, after years of serving, asphalt concrete gets damaged under cyclic vehicle loading. Meanwhile, due to environmental effects including ageing and moisture damage, asphalt binder becomes brittle with time. As a result, microcracks initiate and grow into larger scales, which accelerates the damaging process and finally leads to distresses like raveling, potholes, cracking, and so on.

In 1967, Bazin and Saunier ${ }^{[1]}$ witnessed and reported a temperature related healing phenomenon in asphalt mix after loadings. After that, the healing phenomenon of bituminous material has become a research focus.

On different scale levels, the asphalt concrete shows various self-healing behaviors. $\mathrm{Qiu}^{[2]}$ has explained it in macrolevel and mesolevels: at macrolevel, some of the microcracks can be healed during the rest periods between two axle passages, and also during summer when the temperature is high. At mesolevel, healing can be observed both in the cohesive and adhesive regions of asphalt mixtures. Healing is considered
Healing is the reparation of a chemical structure in such a way that microfatigue damage is decelerated. It is related to the composition and the physicochemical characteristics of bitumen and asphalt mixes.

\section{ii) Mechanical Way}

Williams et al. ${ }^{[4]}$ found that microdamage healing is real and measurable and that it has a significant impact on pavement performance. The stress wave test was used to measure microcrack damage growth and study the healing of asphalt concrete pavements in the field, and they found that healing does occur in pavements in the field during rest periods which suggests that the performance and service life of the pavement will be increased if rest periods are introduced.

The healing phenomenon of asphalt can also be explained with the molecular interactions within asphalt. In 1990, Kim et al..$^{[5]}$ proved that the healing rate for different asphalt mixtures is related to the molecular characteristics of their respective asphalt binders. That is, the methyl hydrogen to carbon ratio and the methylene to methyl group ratio. Later on, Bhasin et al. ${ }^{[6]}$ used the asphalt binder molecules' selfdiffusivity theory to explain the time-dependent healing
S. Xu, Dr. A. Tabaković, Prof. E. Schlangen

Faculty CITG

Delft University of Technology

Delft 2628CN, The Netherlands

E-mail: Erik.Schlangen@tudelft.nl

Dr. Á. García

Nottingham Transportation Engineering Centre [NTEC]

Department of Civil Engineering

University of Nottingham

Nottingham NG7 2RD, UK

Prof. J. F. Su

School of Materials Science and Engineering

Tianjin Polytechnic University

Tianjin 300387, China

The ORCID identification number(s) for the author(s) of this article can be found under https://doi.org/10.1002/admi.201800536.

\author{
Dr. Q. Liu \\ State Key Laboratory of Silicate Materials for Architectures \\ Wuhan University of Technology \\ Wuhan 430070, China \\ Dr. A. Tabaković \\ Research, Enterprise and Innovation \\ Dublin Institute of Technology \\ Dublin D06H328, Ireland \\ Dr. A. Tabaković \\ School of Civil Engineering \\ University College Dublin \\ Dublin D04V1W8, Ireland
}

DOI: 10.1002/admi.201800536 
effect in asphalt. The term self-diffusivity refers to the diffusion coefficient of a species of molecules of a material within the bulk of that material. Self-diffusivity represents random motion of molecules in the absence of gradients that cause mass flux. Based on this theory, Bhasin et al. ${ }^{[7]}$ used molecular simulation techniques to investigate the correlation of chain length and chain branching to self-diffusivity of binder molecules. The findings were consistent with previous studies and expanded on the understanding of the relationship between molecular architecture, self-diffusivity, and self-healing properties of asphalt binders. In 2014, Hou et al. ${ }^{[8]}$ explained self-healing mechanism of asphalt by using a phase-field model. In this model, the thermodynamic approach and mechanical approach are combined, which provided a better understanding of the healing mechanism of asphalt.

Although the intrinsic healing capacity of asphalt has been proved, the asphalt intrinsic healing effect is limited by the field condition and is not enough to match the deterioration process. ${ }^{[2]}$ Therefore, researchers are exploring novel methods to inspire the potential healing capacity of asphalt. Subsequently, various healing methods have been proposed, including nanoparticles, ${ }^{[9]}$ induction healing, ${ }^{[10-14]}$ and embedded rejuvenator encapsulation. ${ }^{[15-22]}$

In the last 10 years, the self-healing technologies in asphalt have been developed rapidly. In particular, some novel methods have been applied in trial section, like the induction healing section A58 in the Netherlands, ${ }^{[23]}$ European HEALROAD project, ${ }^{[24]}$ and the microcapsules healing section in China. ${ }^{[25]}$ All these achievements reveal a closer step to the successful large scale application of self-healing technologies in asphalt.

The current article provides a technical overview of the latest novel methods related to self-healing asphalt and field applications. By doing this, the authors attempt to contribute to the development of self-healing technologies in asphalt by highlighting the current research achievements and inspiring additional future self-healing methods.

\section{Induction Healing}

It is well known that asphalt concrete can repair its own damage and recover its strength and fatigue life autonomously during rest periods. ${ }^{[4,26-29]}$ Researches have demonstrated that temperature is the dominant factor influencing the self-healing properties of asphalt concrete: an increase in the test temperature not only increases the self-healing rate but also shortens the total time needed for full healing. ${ }^{[2,30]}$ To enhance the self-healing capacity of asphalt concrete through increasing the temperature, an induction heating approach was developed at Delft University of Technology. Steel fibers were added to asphalt mixtures and induction heating was applied to increase the healing capacity of asphalt concrete when cracks occurred in asphalt mastic. ${ }^{[1131-33]}$ During induction heating, asphalt mortar containing conductive particles are exposed to a high-frequency alternating electromagnetic field, which is able to induce eddy currents in materials that are electrically and magnetically susceptible. The metallic fibers were heated by the induced eddy currents and the heat energy diffuses into

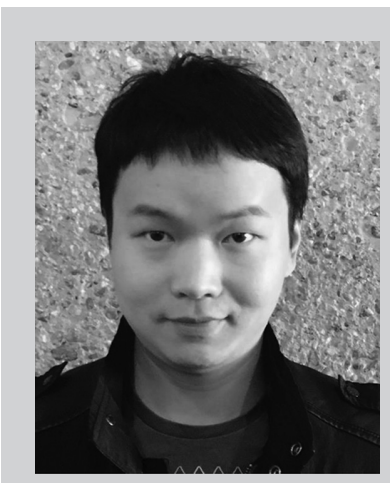

Shi $\mathrm{Xu}$ is a PhD candidate from Material \& Environment Section at the Faculty of Civil Engineering and Geosciences at Delft University of Technology in the Netherlands. His research focus is to improve the healing capacity of asphalt pavement with self-healing technologies. His calcium alginate capsules healing system has been proved to have significant healing effect in asphalt. He is specialized in asphalt design, material testing, healing effect evaluation, and numerical simulation.

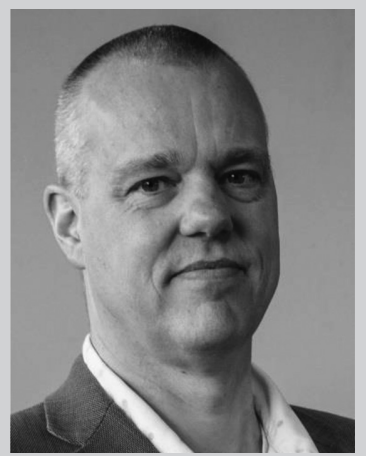

Erik Schlangen is Professor in the chair of "Experimental Micromechanics" and head of the Material \& Environment Section at the Faculty of Civil Engineering and Geosciences at Delft University of Technology in the Netherlands. He is also the Director of the Microlab for micromechanical and material research which is part of the same university. He is specialized in fracture mechanics of quasi-brittle materials like concrete, durability mechanics, finite element modeling, design of experimental techniques, and self-healing of concrete and asphalt.

the bitumen to increase the temperature. Asphalt mixture can be healed quickly because bitumen behaves as a Newtonian fluid when its temperature is above the softening point of bitumen. ${ }^{[34-36]}$

\subsection{Induced Healing of Asphalt Concrete via Induction Heating}

\subsubsection{Preparation of Asphalt Concrete Containing Steel Fibers}

To make asphalt concrete electrically conductive and suitable for induction heating, conductive fibers were usually incorporated into the mixture. Normally, steel fibers were directly added into the mixture during mixing without changing the gradation of the mixture. ${ }^{[11,31,32]}$ Figure 1 shows the typical distribution of steel fibers in the mixture, where steel fibers form conductive paths and serve as the heating units. Long steel fibers are more effective to enhance the conductivity and induction heating speed of asphalt mixture, ${ }^{[10]}$ but they are very difficult to mix and tend to form clusters, which will absorb too much bitumen and decrease the mechanical properties of 


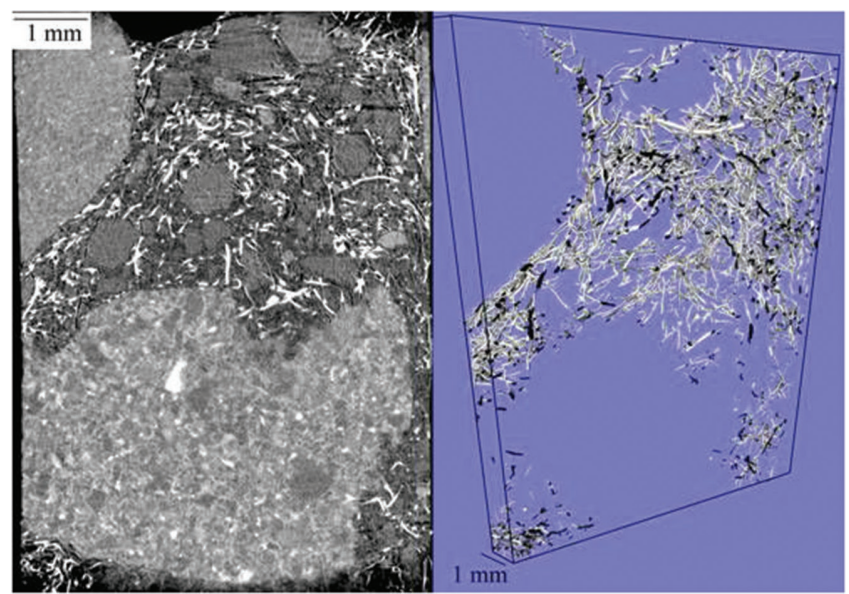

Figure 1. CT-scan reconstruction of the distribution of steel wool in the mixture.

the mixture. Short and thick steel wool fibers with diameter $70-130 \mu \mathrm{m}$ and length $4.2 \mathrm{~mm}$ are recommended in the latest research. ${ }^{[37]}$ This steel wool fibers are quite easy to mix with the normal mixing procedure and their optimal content is $6 \%$ by volume of bitumen. This steel wool fiber can increase Marshall stability, residual Marshall stability ratio, water stability, raveling resistance, fatigue resistance, and low temperature properties of asphalt mixture. The composite of steel fibers and steel slag (replacing a portion of mineral aggregates with steel slag) can enhance the induction heating speed, the heating homogeneity, and thus enhance the induction healing ratio of asphalt mixture. ${ }^{[38]}$

\subsubsection{Heating Characteristics of Asphalt Mixture with Induction Heating}

Asphalt beams with a length of $200 \mathrm{~mm}$, width of $40 \mathrm{~mm}$, and height of $80 \mathrm{~mm}$ (steel wool fiber content was $6 \%$ by volume of bitumen) were heated by an induction machine with output power of $8.3 \mathrm{~kW}$ and frequency of $123 \mathrm{kHz}$. The settings and specifications of the induction machine actually determine the capabilities and the speed for heating the asphalt surface. In this section possible implications for a certain machine are discussed. These are not general, but indicate the possible problems. An infrared camera was used to monitor the temperature profile in the beam during heating. The distance between the coil and the surface of the beam was kept at $10 \mathrm{~mm}$ to obtain a high heating speed.

The magnetic field intensity is not homogenously distributed under the coil of the induction heating generator, which results in inhomogeneous heating in asphalt mixture. Even at the top surface of the sample, there is also a temperature gradient. Figure 2 shows the temperature distribution at the surface of the sample after heating $70 \mathrm{~s}$, where most parts $(80.7 \%)$ of the top surface of the sample have a temperature between 100 and $120^{\circ} \mathrm{C}$ and the mean temperature is $107.2{ }^{\circ} \mathrm{C}$.

The infrared image and vertical temperature distribution of the beam after $60 \mathrm{~s}$ induction heating were shown in Figure 3. It can be seen from the infrared image that the temperature

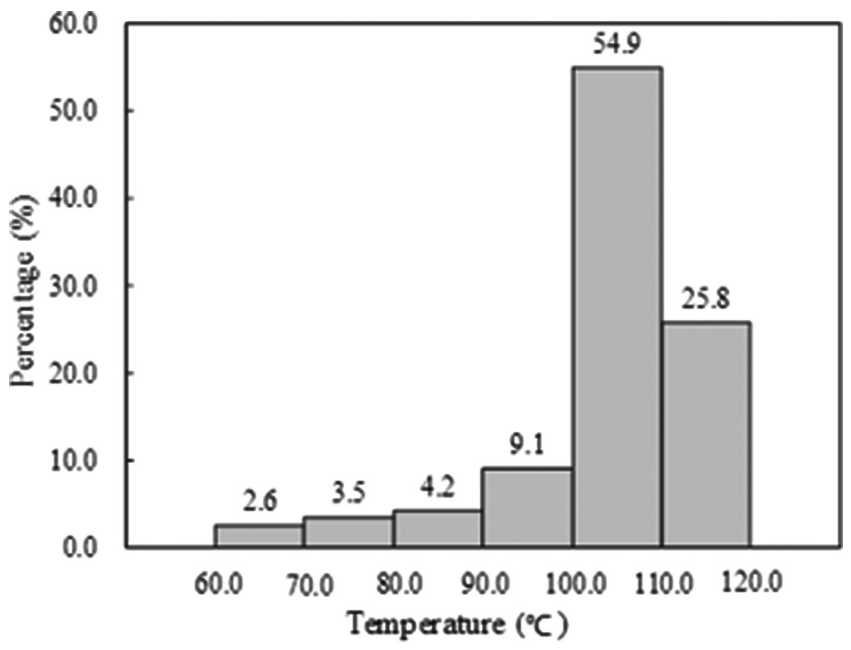

Figure 2. Temperature distribution at the top surface of the sample.

distribution showed an uneven heating effect in the vertical direction. The average temperatures of the top half and the lower part of the beam were 72.1 and $39.4{ }^{\circ} \mathrm{C}$, respectively, the temperature difference between the top half and the lower part reached $32.7^{\circ} \mathrm{C}$. It is worth noting that the ratio above $46.6^{\circ} \mathrm{C}$ (around softening point of asphalt) was 55\%, meaning that half of the cracks can be healed at the optimal temperature.

The temperatures at different depths of the sample with different induction heating time were shown in Figure 4. It can be seen from Figure 4 that the temperature difference between the surface and the bottom of the sample increased with increasing heating time. The surface temperature reached $55.5^{\circ} \mathrm{C}$ after $20 \mathrm{~s}$ heating, while the bottom temperature was only $27.5^{\circ} \mathrm{C}$, resulting in a temperature difference of $28{ }^{\circ} \mathrm{C}$. The temperature difference between the surface and the bottom of the sample reached $92.3^{\circ} \mathrm{C}$ after $100 \mathrm{~s}$ heating. It means that temperature distribution within the sample is much uneven. It can also be seen from in Figure 4 that the vertical temperature change rate increased from 0.35 to $1.15{ }^{\circ} \mathrm{C} \mathrm{mm}^{-1}$ with heating time increasing from 20 to $100 \mathrm{~s}$. The existence of the huge

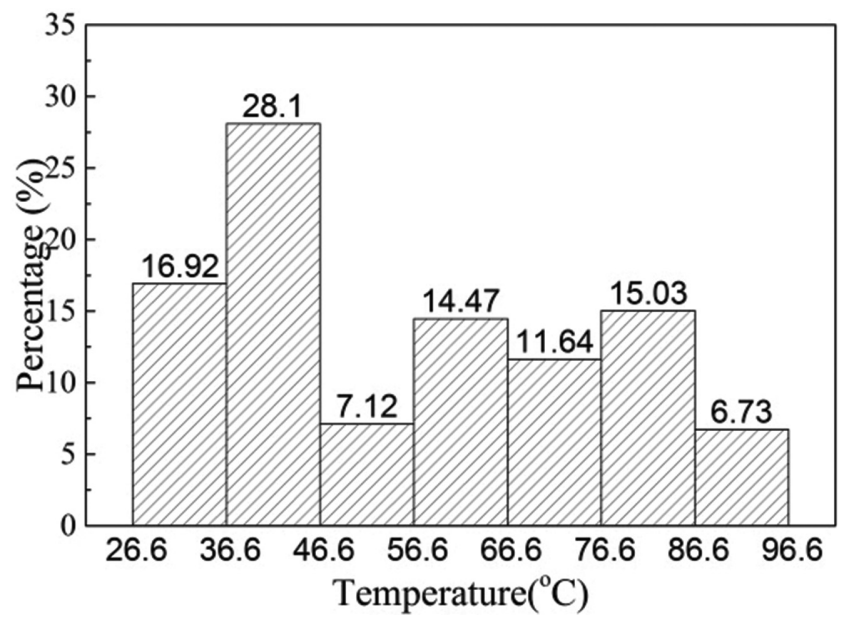

Figure 3. Vertical temperature distribution of the sample with induction heating $60 \mathrm{~s}$. 


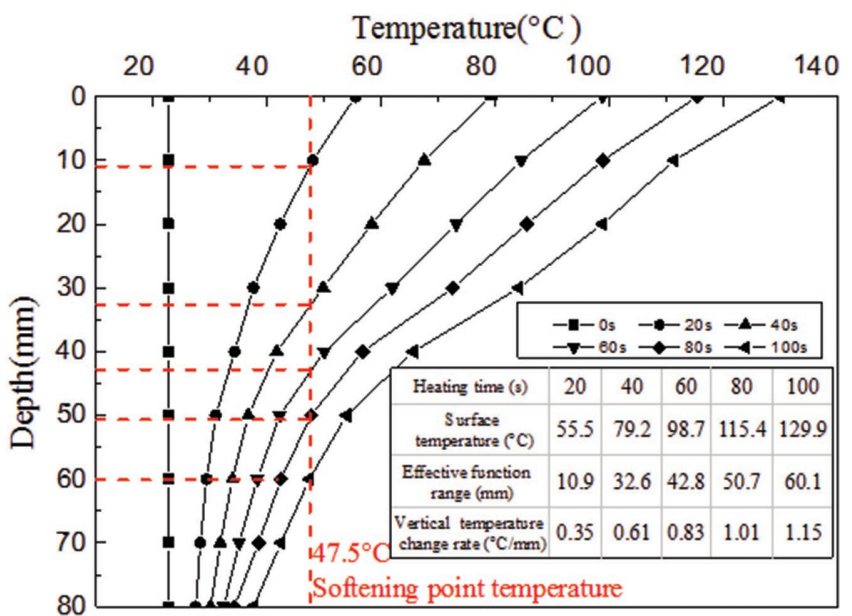

Figure 4. Vertical temperature distribution of the samples after different induction heating time.

temperature difference will have a great influence on the crackhealing behavior of the samples.

It can also be seen from Figure 4 that the heating speed decreased gradually with the deepening of the depth. The temperature at the depth of $80 \mathrm{~mm}$ only increased by $14.9^{\circ} \mathrm{C}$ after $100 \mathrm{~s}$, which is not sufficient to activate the healing of the binder. So, an effective healing depth exists after each heating time and it is less than the thickness of the samples.

The healing efficiency of asphalt mixture depends on the capillary flow speed of bitumen. The softening point of bitumen can be considered as a good healing temperature. The softening temperature of $70 \#$ base bitumen used in this research was $47.5{ }^{\circ} \mathrm{C}$. Therefore, the depth at which the temperature reached $47.5{ }^{\circ} \mathrm{C}$ was considered as effective healing depth of the sample and the effective healing depths at different heating time were shown in Figure 4. It can be seen that the effective healing depth increased with the increase of the heating time. The effective healing depth reached $10.9 \mathrm{~mm}$ after $20 \mathrm{~s}$ heating, while increased to $60.1 \mathrm{~mm}$ after $100 \mathrm{~s}$. However, the surface temperature of the sample reached $129.9^{\circ} \mathrm{C}$ after $100 \mathrm{~s}$ heating, and the beam sample suffered serious deformation. As shown in previous research, the surface heating temperature should not be higher than $100{ }^{\circ} \mathrm{C}$ to avoid the swelling of the binder and the excess expansion of the mixture; it can be assumed that the maximum effective depth of asphalt mixture with induction heating is around $42.8 \mathrm{~mm}$ with $60 \mathrm{~s}$ heating. Extending the heating time further will result in excess expansion deformation of the mixture.

\subsubsection{Fatigue Life Extension of Asphalt Concrete with Induction Healing}

The experimental method of testing the induction heating activated healing of fatigue damage in asphalt beams consisted of three steps: 1) fatigue testing at $15{ }^{\circ} \mathrm{C}, 10 \mathrm{~Hz}$, and with 600 microstrain was performed on asphalt beams $(380 \mathrm{~mm} \times 63.5 \mathrm{~mm} \times 50 \mathrm{~mm})$ until the complex modulus dropped to half of its initial value; 2 ) the fatigue damaged

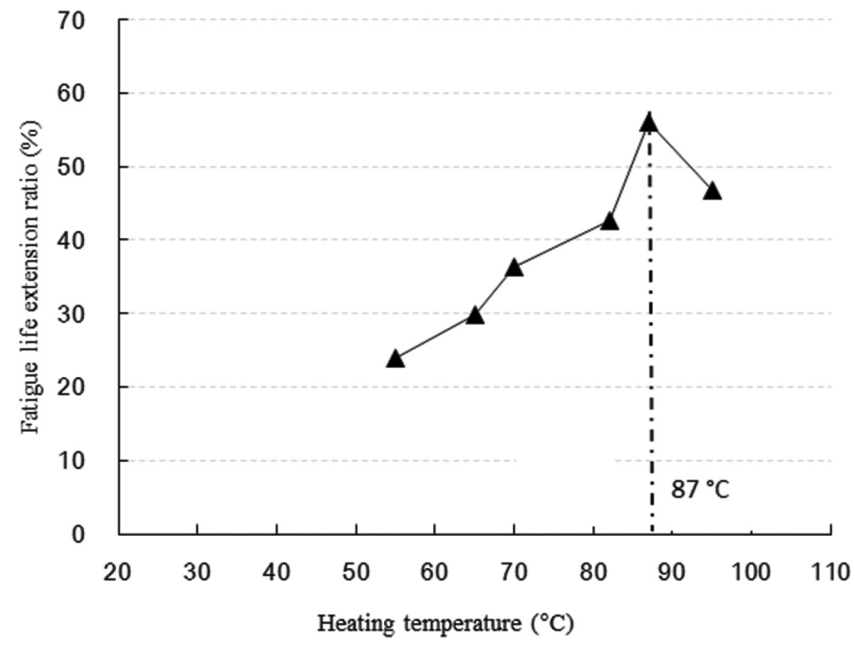

Figure 5. Fatigue life extension ratios of the samples versus heating temperature.

beams were heated to different temperatures, and 3) finally the heated beams were cooled to $15^{\circ} \mathrm{C}$ and tested again under fatigue until the complex modulus dropped to the same value as the first fatigue testing. The second fatigue life is a healing indication caused by resting and induction heating. The healing index fatigue life extension ratio can be defined as the second fatigue life divided by the original fatigue life.

The effects of heating temperature and microstrain amplitude on asphalt healing rates were explored. As shown in Figure 5, the healing ratios of the samples are significantly influenced by temperature. In Figure 6, the maximum fatigue life extension of testing sample happened at 400 microstrain. The fatigue life extension is decreased at a lower microstrain amplitude. While at higher microstrain amplitudes, larger cracks were generated in the fatigue testing which is hard to heal.

The possibility of multiple instances of induction heating also was examined to show that induction heating could be repeated when cracks return after healing. A strain amplitude

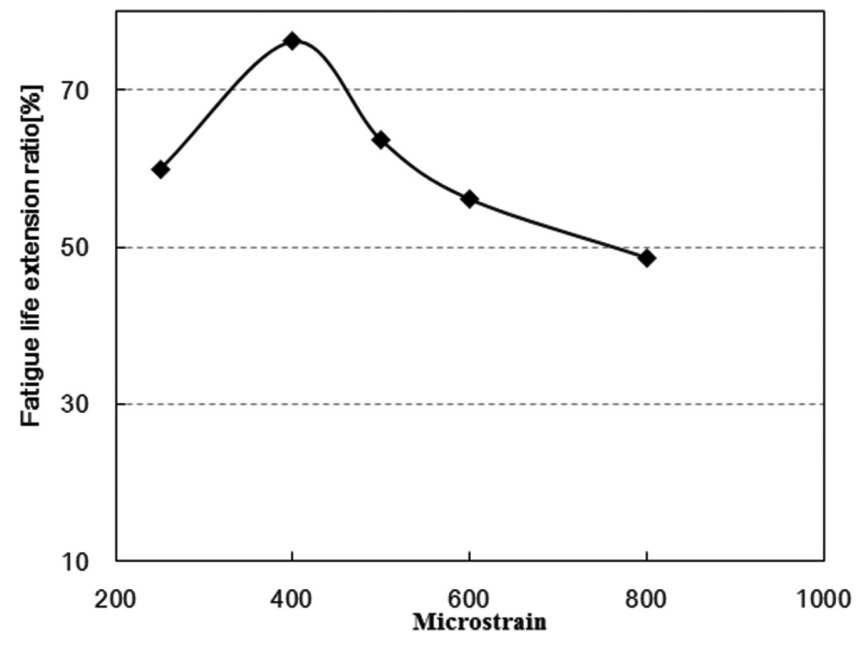

Figure 6. Fatigue life extension ratios of the samples under different microstrain amplitudes. 


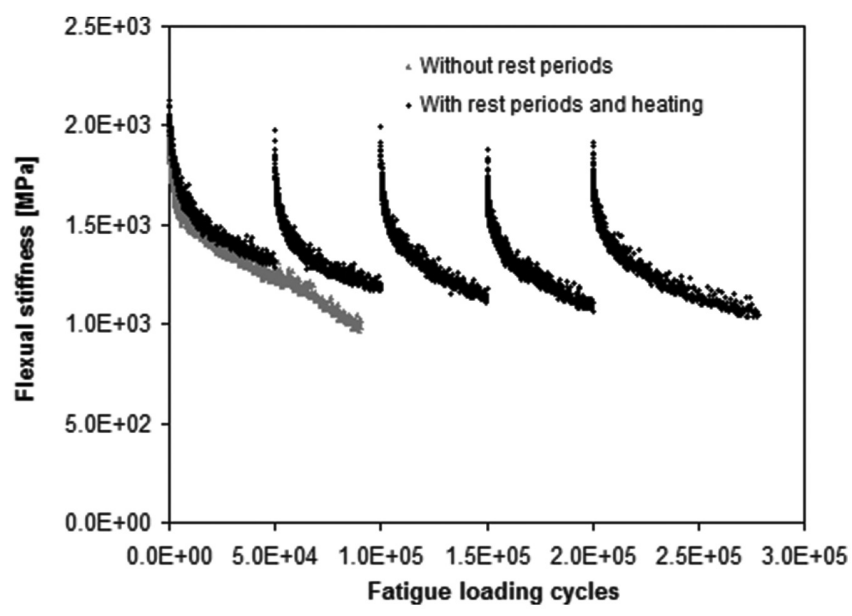

Figure 7. Fatigue life extension of the sample caused by multiple induction heating. Reproduced with permission. ${ }^{[39]}$ Copyright 2012, Elsevier Ltd.

of 300 microstrain at a frequency of $8 \mathrm{~Hz}$ was applied to the porous asphalt concrete beams for 50000 cycles. Then, samples were induction heated to $85^{\circ} \mathrm{C}$ and rested for $18 \mathrm{~h}$ for the first time. After that, another 50000 cycles of fatigue loading were applied to the beams, followed by a second heating and resting process. The damaging, heating-and-resting, and redamaging program was repeated four times. Finally, the beam fatigue life was measured. ${ }^{[38]}$

Figure 7 compares the original fatigue curve and the modified fatigue curve for sample with multiple instances of induction heating to show the fatigue life extension caused by induction heating. The original fatigue life of the sample is 95700 cycles. With four instances of damage loading of 50000 cycles followed by four instances of induction heating and resting, the modified fatigue life is 277 720, which is 2.9 times the original fatigue life; the fatigue life extension ratio was $190 \%$ in this case. Even though this research does not fully optimize when to heat the pavement and heating frequency, multiple instances of heating definitely can greatly extend the fatigue life of asphalt concrete.

\subsubsection{Strength Recovery of Asphalt Concrete with Induction Heating}

The test procedure for measuring induction heating induced healing of fracture damage in asphalt beams $(250 \mathrm{~mm} \times 35 \mathrm{~mm}$ $\times 30 \mathrm{~mm}$ ) consisted of three steps: 1) Fracture the asphalt beam in three point bending test; 2 ) Heat the fractured beam and let the heated beam rest for $4 \mathrm{~h}$; 3 ) Fracture the healed beam again in three point bending test with the same displacement speed. The recovered flexural resistance of the fractured beam can be used as a healing indicator. The healing index was defined as the recovered flexural resistance divided by the original flexural resistance. ${ }^{[12]}$

Figure 8 shows the strength recovery ratios of the samples at different heating temperatures. The fractured beam sample could not recover its strength at room temperature and lower temperatures. The strength recovery ratio of the beams increased with the increasing heating temperature.

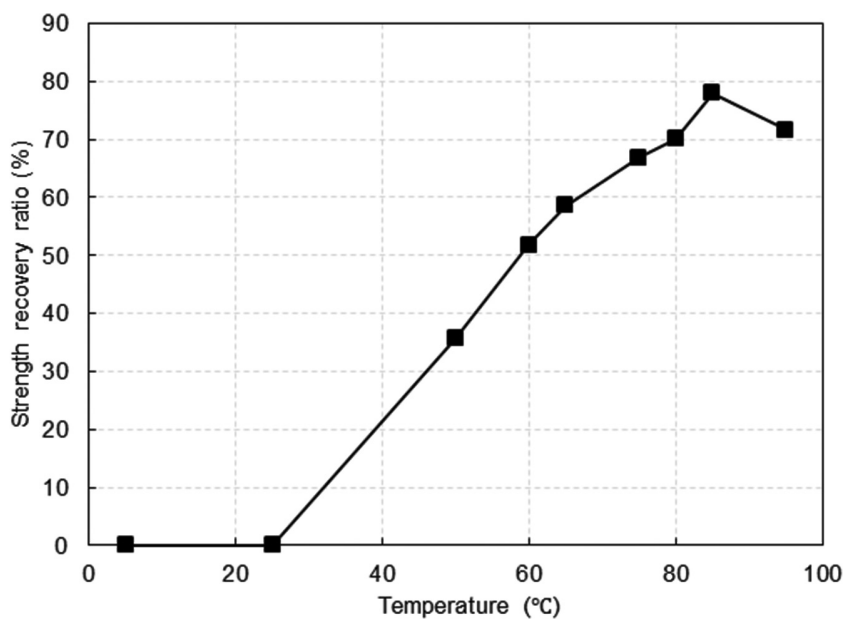

Figure 8. Strength recovery ratios of the samples at different heating temperatures.

The healing of bitumen and asphalt mixtures can be regarded as a thermally activated process of capillary flow and diffusion of the binder. ${ }^{[12]} \mathrm{A}$ higher temperature will benefit the healing process, while overheating will damage the structure. Swelling of the mortar can be observed in the samples heated to $95{ }^{\circ} \mathrm{C}$. Binder drainage may also occur in these overheated samples, and that can also offset the beneficial effect of heating. Based on this result, it is concluded that the optimal heating temperature is $85^{\circ} \mathrm{C}$. ${ }^{[12]}$

The maximum strength recovery of the fractured beam is $77.9 \%$, which means the induction healing is not complete $(100 \%)$. One possible reason for the incomplete healing mainly lies in the fact that some aggregates were broken during the test, which cannot be recovered. Another possible reason could be the temperature gradient through the depth of the sample. The sample is fully damaged through its height, but induction heating tends to only heal the damage in the top part of the beam, where the temperature is higher than in the lower part after induction heating. ${ }^{12]}$

To investigate the possibility of rehealing, a five-timerepeated cyclic fracturing-healing program was followed. The notch in the sample allowed the crack to occur at the same place all the time. The heating temperature is fixed at $85{ }^{\circ} \mathrm{C}$ to obtain the optimum healing. Figure 9 shows the results of the cyclic fracturing-healing test. In Figure 9, the fracture resistance of the healed beam stays constant during the cyclic fracturing-healing test, which indicates that it is possible to repeat the induction healing for at least five times if crack appears, as induction heating does not decrease the healing ratio of the fractured beam. It also indicates that there is no accumulated damage or permanent deformation in the sample during the cyclic fracturing-healing test on an elastic foundation. Otherwise, the first time healing ratio would be higher than the latter ones. $^{[12]}$

\subsubsection{Application of Induction Heating on Asphalt Pavement}

The first trial section with the induction heating concept was constructed on highway A58 near Vlissingen in the Netherlands 


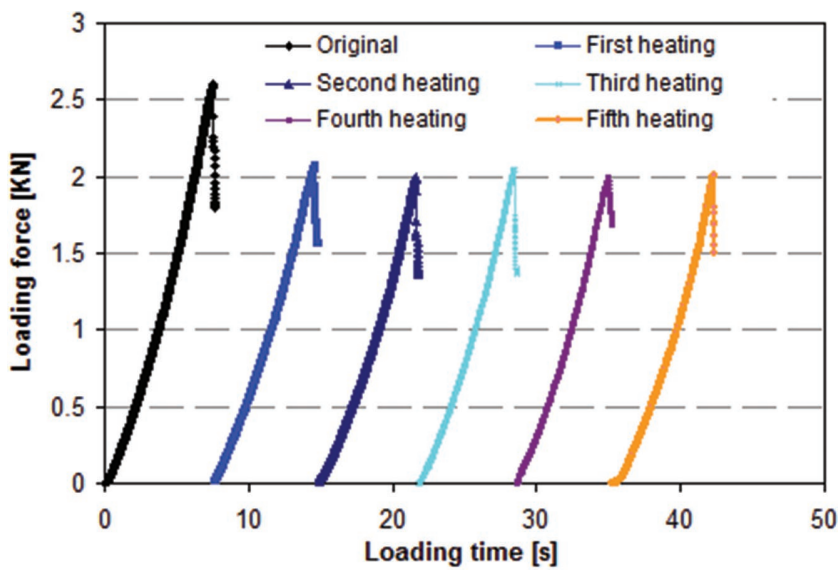

Figure 9. Loading force-loading time curves of the cyclic fracturinghealing test. Reproduced with permission. ${ }^{[12]}$ Copyright 2012, American Society of Civil Engineers.

in 2010. This trial section showed better raveling resistance and good healing ratios with induction heating. The first induction heating treatment was applied on it in June 2014 (Figure 10).

It was estimated that the Netherlands can save about 90 million euro annually by investing in induction healing asphalt concrete with a $50 \%$ extended life span and twice of the price compared with standard asphalt concrete. And China will save a maintenance expense of 1000 billion RMB in the life span by applying induction healing concrete in $10 \%$ of its asphalt pavement. Thus, induction healing asphalt concrete, being a smart material and an advanced maintenance concept for asphalt pavement, is promising to greatly improve the quality of the pavement, reduce the maintenance activities, and extend its service life. ${ }^{[3]}$

\subsection{Induced Healing of Asphalt Mixture via Microwave Oven Heating}

Similar to induction heating, microwave heating is also considered as a promising technique to promote self-healing of composite materials. Microwave heating causes the polar molecules orientation change as a result of the alternating magnetic field. As a result, the movement of the molecules is disturbed and hindered and the temperature rises. Normal asphalt mixture can be heated with induction heating energy, but if metallic particles are added to the mixture, these may reflect microwave radiation and accelerate the increase of temperature. Thus, ferrous particles can be used to increase heating rates of asphalt
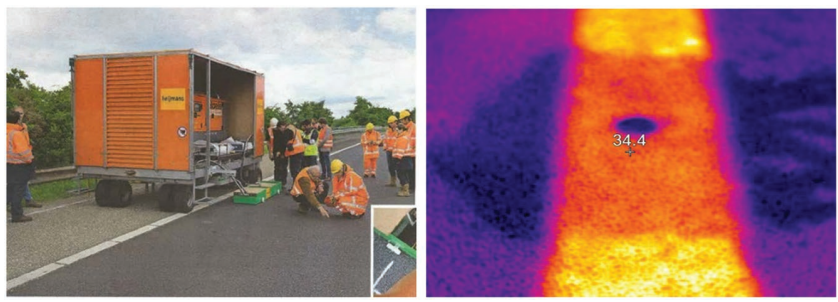

Figure 10. Application of induction heating on Dutch Highway A58. mixtures because they can absorb and conduct more thermal energy than the other components of the mixtures, aggregates and bitumen. Laboratory experiments have been conducted by adding steel fibers into asphalt mixture to get induced-healing of asphalt mixture. ${ }^{[13,14,40]}$

\subsection{HEALROAD Project: Using Induction Heating Technique to Increase Road Durability and Reduce Maintenance Costs and Disruptions}

A second method to promote asphalt self-healing consists in increasing the temperature of the road areas that present microcracking before damage becomes visible in the road surface. To do this, it is required to embed electrically conductive and magnetically susceptible particles, such as steel fibers, in the asphalt road's surface layer. ${ }^{[32]}$ When the highway owner recognizes that a road requires maintenance, an inductionheating machine will circulate at a walking pace, heating the road surface layer. Heat is generated through the energy lost when eddy currents meet with the resistance of the electromagnetic embedded particles. ${ }^{[31]}$ Because of the increase of temperature, the viscosity of bitumen will reduce and its volume will increase due to thermal expansion, flowing into and filling the cracks. ${ }^{[41]}$

The HEALROAD project (induction heating technique to increase road durability and reduce maintenance costs and disruptions) was funded by the European Research Area Network (ERA-NET) Plus Infravation 2014 research call that aimed to design cost-effective advanced systems, materials, and techniques for road infrastructure construction and maintenance. The aim of this project was to perfection a durable and economic road that could be repaired by means of induction energy. Partners of the project were the Universities of Nottingham and Cantabria, SGS Intron B.V., Bundesanstalt für Straßenwesen (BAST) and Heijmans B.V.

The first objective of the research was to select the fiber modification content that would produce optimized dense and porous asphalt mixture for induction heating road surfaces. Steel fibers with different shapes and from a wide range of origins (Figure 11), such as steel wool fibers, fibers from recycled tyres, workshop's steel scraps and, steel grit, were mixed in dense and porous asphalt mixture, in percentages that ranged from $0 \%$ to $1 \%$. Metallic particles were added to the mixtures without replacing aggregates of equivalent size and the properties that were evaluated were skidding resistance, particle loss, indirect tensile strength, fatigue strength, and induction heating.

The objective of this project was to upscale the inductionheating technology, with the aim of testing it on-site. With this purpose, the correct mixing procedure in an asphalt mixing plant was determined and, the quality of the optimized asphalt mixture after manufacturing it in an asphalt plant was tested. Additionally, a full-scale size induction-heating machine that was optimized to increase the temperature of such asphalt mixture was designed (Figure 12a,b). Finally, the accelerated pavement testing facilities available at BAST (duraBAST) (Figure 12c) that is able to simulate several years of traffic in just a few days, were used to select the equivalent number of axle loads that are 
(a)

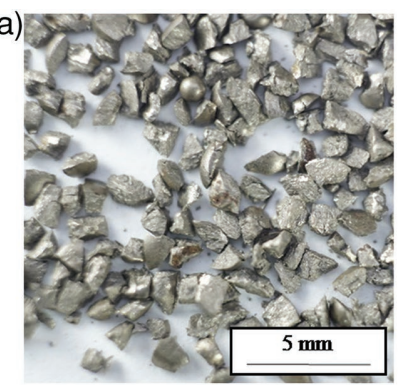

(c)

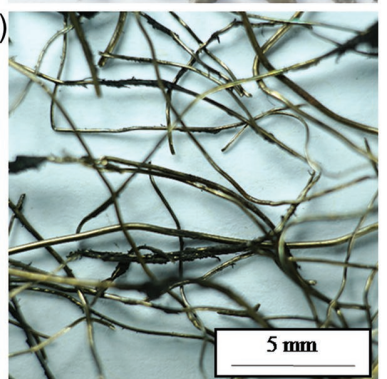

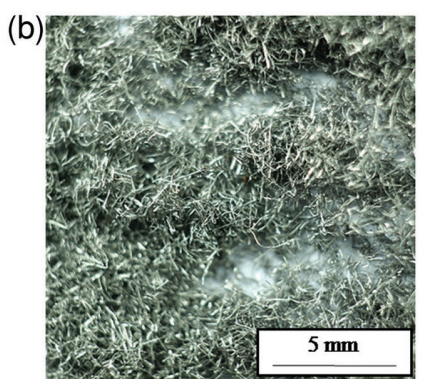

(d)

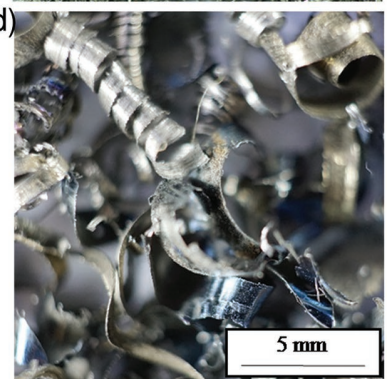

Figure 11. Fibers and particles tested in the HEALROAD project. a) Steel grit; b) steel wool; c) steel fibers from recycling tyres; d) steel shavings.

required before using the induction heating machine in a road subjected to real traffic.

In the HEALROAD project, the self-healing capacity of asphalt mixture was defined by two different methods. First, as the relationship between the 3-point bending strength of an asphalt beam, at $-20{ }^{\circ} \mathrm{C}$, before and after applying induction heating. ${ }^{[4]}$ Secondly, as the increase of durability of an asphalt beam that has been subjected to 3-point fatigue bending and induction heating at some point during the fatigue testing, when compared to the durability of a beam subjected to 3-point fatigue bending where induction heating has not been applied.

With the first testing method, it was found that induction heating can repair individual cracks in dense and porous asphalt beams up to $80 \%$ of their original strength. The reason for this is that during 3-point bending fracture at $-20{ }^{\circ} \mathrm{C}$ some aggregates broke and these cannot be healed. By using this testing method, there was no particular difference between dense and porous asphalt mixture. ${ }^{[41]}$

With the second testing method, it was found that induction heating increases the lifetime of porous asphalt surfaces more than the lifetime of dense asphalt surfaces. The reason is that denser asphalt mixtures tend to deform before cracking, which

cannot be repaired by means of induction energy, while porous asphalt mixtures tend generate microcracks in the mastic between aggregates and can be repaired with induction energy. Besides, induction heating of dense asphalt mixture may damage the material and cause bitumen segregation. For this reason, it was concluded that induction heating will work excellently to repair and prevent microcrack-related effects in porous asphalt mixture, such as raveling, while it will be ineffective to repair cracks in dense asphalt mixture, such as bottom-up cracks.

The type of fibers that could be better used for asphalt induction heating, with regard to excellent mixability, improved particle loss, and induction-heating properties, was steel wool, with individual fibers of $40 \mu \mathrm{m}$ diameter and less than $2 \mathrm{~mm}$ length. Moreover, $\approx 0.3 \%$ of the total weight of the mixture was recommended as the optimum amount of fibers to maximize asphalt induction heating, without affecting the mechanical properties and mixability of the asphalt materials. This amount of metal increased the price of asphalt mixture in $\approx 30 \%$. The other types of metallic fibers and particles tested presented different disadvantages, such as uneven distribution in the asphalt, increased friction, and increased air void content and they were discarded for these reasons. By using this type of steel wool fibers, no special and exceptional procedures are needed to produce the novel mixtures and standard production plant is suitable with the usual way of adding additives.

It was found that the type of bitumen used does not have a significant effect on the self-healing rate of asphalt mixture when it is promoted by induction energy. In addition, the final temperature reached by asphalt mixture during induction heating did not influence its final self-healing level and the most important factor affecting the final selfhealing of asphalt mixture was its heating speed: the faster, the better. To validate this point, the temperature of asphalt beams was increased by means of infrared lamps instead of using the induction-heating machine, which reduced the heating rate from seconds to hours. It was found that even when the final temperature of asphalt mixture could be $1 / 3$ higher if infrared heating was used, for example, from 90 to $120^{\circ} \mathrm{C}$, the final healing level reached could be lower, for example, from $\approx 80 \%$ to $\approx 60 \%$ recovery. Moreover, when cracked asphalt beams were heated using infrared energy, the healing level reached a peak until the moment when the steady state temperature was achieved and it reduced $\approx 20 \%$ in the subsequent hours.

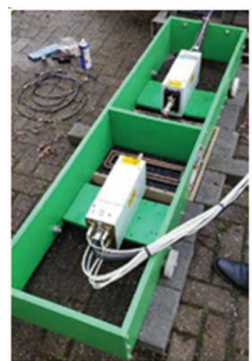

(a)

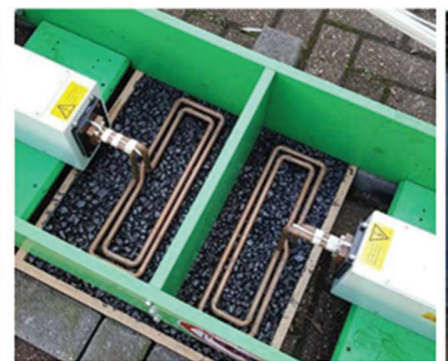

(b)

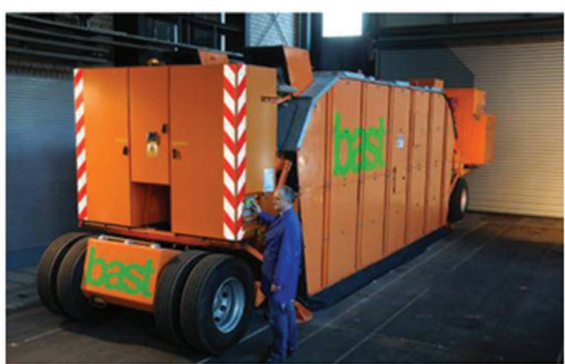

(c)

Figure 12. a,b) Left and Center: View of the induction heating machine unit. c) Right: Mobile Load Simulator 30 (MLS30). 
It was concluded that the main mechanism influencing self-healing is the thermal expansion of bitumen, which is practically constant for the types of bitumen that are conventionally used in roads. After the temperature of asphalt reaches steady-state conditions, the volumetric properties of bitumen remain constant and bitumen flows downward due to gravity. Therefore, cracks tend to reopen from the upper asphalt surfaces. ${ }^{[41]}$

Most importantly, bitumen did not age detectably during induction heating of asphalt mixture. Furthermore, it was found that steel fibers can be added to RAP in order to increase its self-healing capacity and durability, with only a slight reduction of its healing capacity.

The life-size induction heating machine that was selected to test asphalt induction heating at duraBAST had $1400 \mathrm{~V}, 3 \mathrm{~A}$, and worked at $312 \mathrm{kHz}$. The total energy that could introduce in the pavement ranged between 7.0 and $7.5 \mathrm{~kW}$. Two $40 \mathrm{~cm}$ coils were used, together with $4 \times 0.33 \mu \mathrm{F}$ condensers. Accelerated Pavement Testing was applied using a Mobile Load Simulator (MLS30), with super-single 4 loading wheels in closed chain. The load applied was $75 \mathrm{kN}$, at $7 \mathrm{~km} \mathrm{~h}^{-1}$. Shear was simulated by lateral displacements of the wheel of $\pm 350 \mathrm{~mm}$. To quantify asphalt self-healing, the factor that was measured was raveling or stone loss from the surface.

\subsection{General Thoughts about the Future of Self-Healing Asphalt by the Action of Induction Energy}

Asphalt induction-heating has been tested in the laboratory and validated on-site. The technology is ready for its commercial use and it should be taken up by industry to bring the product to the market.

From a research point of view, there is still a challenge to reduce the price of asphalt mixture that contains fibers. A possible solution could be the usage of waste materials that are susceptible to induction heating, such as iron oxide nanoparticles, and the development of binders that contain these waste materials.

It has been shown that asphalt self-healing can be used on porous asphalt. It is believed that it also can be applied for dense asphalt road surfacing; however, more research is needed to prove the benefits for these applications. In addition, for using this technology at its best it is needed to predict the moment when raveling or other damage starts, because that is the moment when highway managers must apply the induction-heating machine. This moment could be determined by applying detection tools and possibly by the use of algorithms that are able to relate big data sets obtained from visual and mechanical characterization of roads to the development of microcracks. These algorithms do not exist yet.

\section{Embedded Rejuvenation Encapsulation}

\subsection{Introduction to the Asphalt Rejuvenation}

It is possible for an asphalt pavement to recover its selfrepair mechanism via the addition of bitumen with a higher penetration value or via the addition of a rejuvenating agent. ${ }^{[42-45]}$

A rejuvenator is an engineered cationic emulsion containing maltenes and saturates. The primary purpose of rejuvenator is to diffuse into the aged binder and restore its original molecular structure to extend the pavement service life. Pavement lifespan is extended by adjusting the properties of the asphalt mix, i.e., reducing its stiffness. ${ }^{[43]}$ Except industrial rejuvenator, Garcia et al. ${ }^{[46]}$ and $\mathrm{Su}$ et al. ${ }^{[47]}$ found that vegetable oil and waste cooking oil can also be used as a rejuvenator. It is possible to use a rejuvenator to heal an early stage cracks thereby preventing further crack propagation and pavement failure. ${ }^{[4]}$ The service life of the asphalt pavement can be extended by several years by applying the rejuvenator to the surface course, while this only applies to the top centimeters of the asphalt pavement. Shen et al. ${ }^{[49]}$ found that no rejuvenators could penetrate further than $20 \mathrm{~mm}$ into asphalt pavement layer, indicating that any damage (cracks) occurring at bottom of the asphalt layer will not be repaired. A further issue encountered when applying the rejuvenator to the asphalt pavement is the necessity for road closures. The rejuvenators may also cause a significant reduction in the surface friction of the pavement and may be harmful to the environment. The inclusion of a rejuvenator into the asphalt mix via microcapsules or microfibers offers the potential to overcome these problems. ${ }^{[19,47,50-53]}$

\subsection{Epoxy Capsules}

Garcia et al. ${ }^{[46,54]}$ successfully produced capsules using porous sand which is used as rejuvenator arraying (absorbing) material, the sand granules are bound together and coated by a hard shell made of an epoxy-cement matrix with a volume percentage of $20.9,13.1,24.9$, and $13.0 \%$ of rejuvenator, porous sand, cement, and epoxy, respectively. The capsules obtained have a mean size of $1.60 \mathrm{~mm}$. The idea is to substitute part of the sand aggregates in asphalt concrete with the microcapsules. When the stress in capsules embedded in the asphalt reaches a certain threshold value, the capsules break and rejuvenator is released. Figure 13 shows epoxy microcapsule morphology.

The microcapsule approach presented a solution for the asphalt self-healing process, as it rejuvenates aged binder, i.e., recovers its original physical and mechanical properties. However, the downside to this approach is that it works only once, i.e., once the healing material is released from the microcapsule it cannot be replenished. ${ }^{[55]}$

Furthermore, these capsules have limited rejuvenator content which requires large quantities of capsules to achieve an effective healing. The addition of large quantities of capsules into the asphalt mix can reduce the quality of the pavement which itself may cause premature pavement failure. Garcia et al. ${ }^{[46,54]}$ and Sun et al. ${ }^{[56]}$ reported that asphalt stiffness was reduced when capsules were added. The possible reason was the release of the rejuvenator.

However, an asphalt mix can be deformed by sand granulates. ${ }^{[57,58]}$ It is possible that the inclusion of capsules, sand like particles, has also contributed to increased asphalt mix deformation, i.e., rutting. 

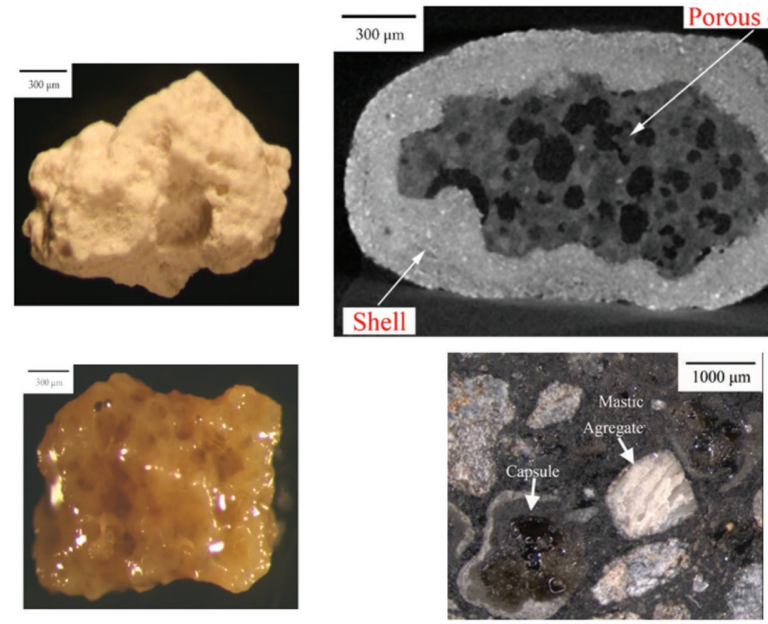

Figure 13. Epoxy microcapsule; top left: porous sand, bottom left: rejuvenator saturated sand granule, top right: microscopic image of epoxy microcapsule encapsulating rejuvenator cross-section, bottom right: embedded epoxy microcapsule in asphalt mix. ${ }^{[46,54]}$ Reproduced with permission. ${ }^{[85]}$ Copyright 2010, Elsevier Ltd.

Nevertheless, this self-healing process is still in the early stage and its full potential will be demonstrated in coming years.

\subsection{Polymer Malamine-Formaldehyde Microcapsules}

Polymer malamine-formaldehyde (MMF) microcapsules encapsulating rejuvenator are successfully manufactured by Su et al. ${ }^{[18,53,59]}$

\subsubsection{Morphologies of Malamine-Formaldehyde Microcapsules}

These microcapsules were manufactured by in situ polymerization method using MMF shell. Hydrolyzed styrene maleic anhydride (SMA) was used as an amphiphilic polymeric surfactant. SMA was hydrolyzed by $\mathrm{NaOH}$ and absorbed at the oily droplets interface. The strong electron negative of rejuvenator droplets reduced the oil/water interfacial tension. Rejuvenator droplets were formed by high-speed mixing. The oil droplets absorbed MMF prepolymer in order to balance the charge. The polymers were cross-linked and then shells were formed. ${ }^{[60]}$

Figure 14a,b shows the morphologies of these microcapsules. The microcapsules keep a regular global shape with a mean size of $100 \mu \mathrm{m}$. The core-shell structure can be recognized from a broken microcapsule in Figure 14c, which means that the oily rejuvenator has been fully encapsulated. Generally, microcapsules with larger diameter are easier to break. As a result, the mean size of microcapsules in asphalt needs to be less than $100 \mu \mathrm{m}$ avoiding squeeze rapture. ${ }^{\left[{ }^{[9]}\right.}$ It has also been found that the $20-50 \mu \mathrm{m}$ is an ideal size for the self-healing microcapsules in asphalt. ${ }^{[18]}$ Polymer shells cannot maintain integrity under an ultimate mechanical strength or thermal stimulation. ${ }^{61]}$ Therefore, it is important that the microcapsules keep regularity and have the appropriate mean size as well as shell thickness. The core/shell ratios controlling method has been reported in previous works. ${ }^{[18]}$

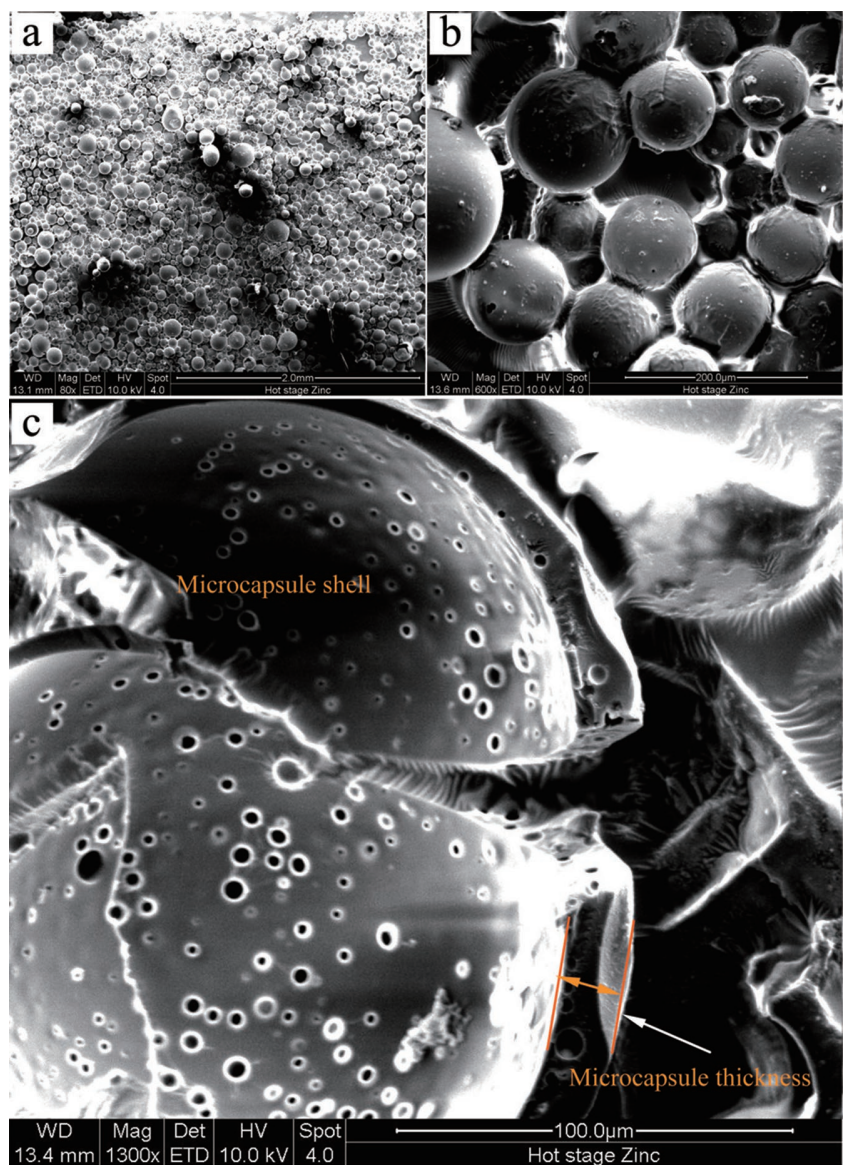

Figure 14. Scanning electron microscope (SEM) morphologies of microcapsules containing rejuvenator. a,b) Microcapsules containing rejuvenator; c) shell structure of a break microcapsule. Reproduced with permission. ${ }^{[60]}$ Copyright 2012, Elsevier Ltd.

\subsubsection{Morphologies and Internality States of Microcapsules in Asphalt Binder}

Figure 15 shows microcapsule samples and asphalt samples mixed with various contents of microcapsules. The amounts of applied microcapsules are calculated based on the content of bitumen. The healing effect of microcapsules has been examined with these asphalt concrete samples.
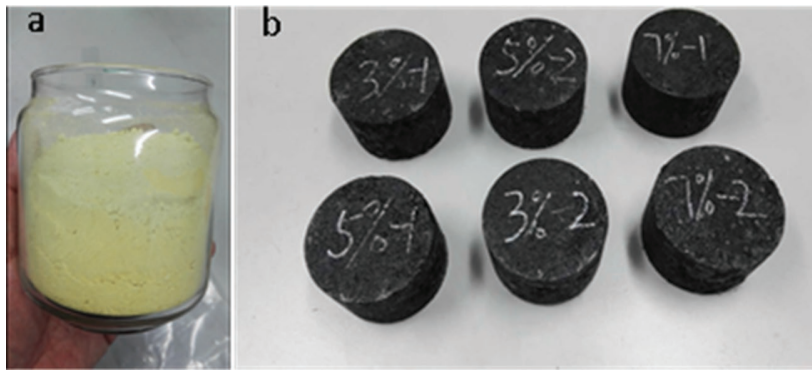

Figure 15. Asphalt samples mixing with microcapsules. a) A photography of microcapsules containing rejuvenator, and $b$ ) a photography of asphalt samples (MB-3, MB-5, and MB-7) mixing with various contents of microcapsules. Reproduced with permission. ${ }^{[60]}$ Copyright 2012, Elsevier Ltd. 

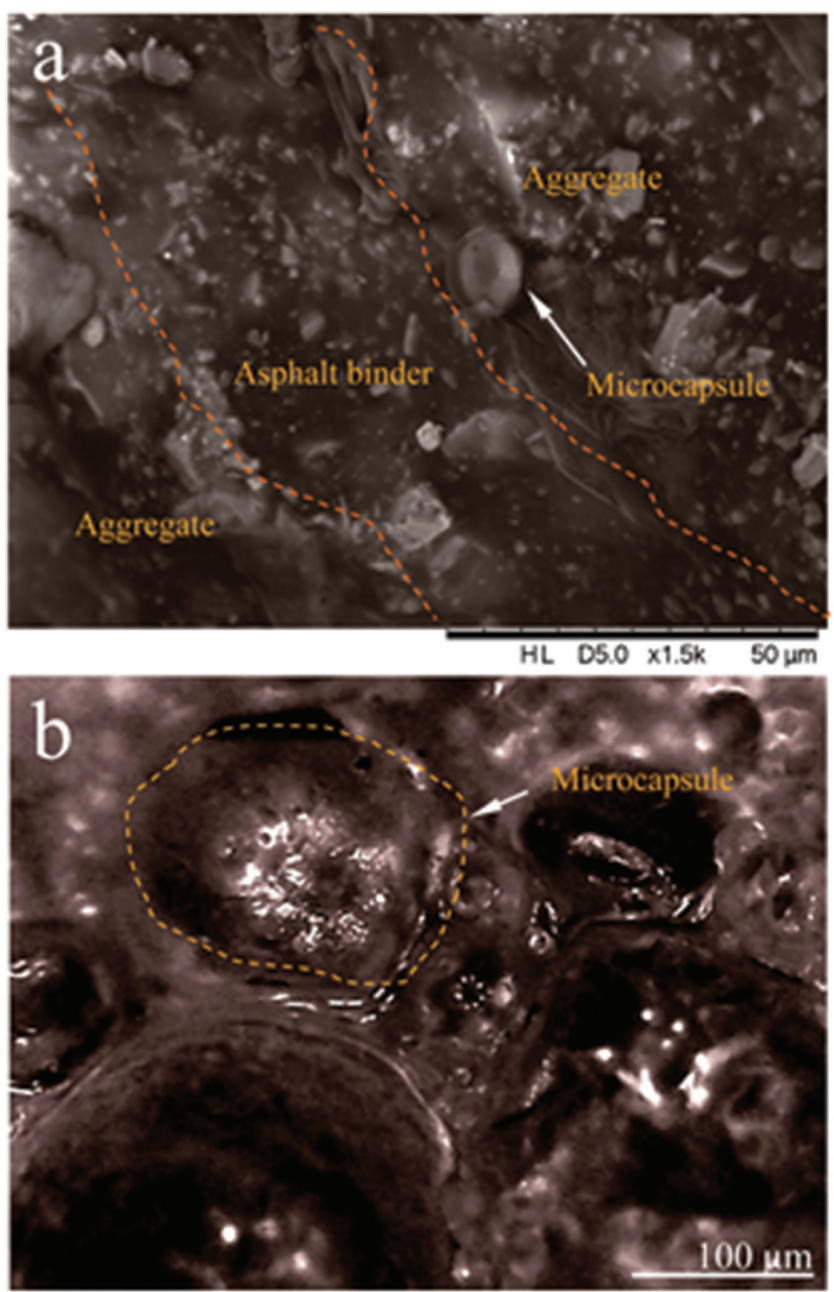

Figure 16. Microstructure morphologies of microcapsules in asphalt sample (MB-7) at room temperature state. a) Environmental scanning electron microscope (ESEM) morphology of asphalt with aggregate and bitumen binder, and b) a fluorescence microscope morphology of microcapsules in bitumen binders. Reproduced with permission. ${ }^{[60]}$ Copyright 2012, Elsevier Ltd.

The microcapsules have been proved to be able to survive under the temperature of $180-200{ }^{\circ} \mathrm{C} \cdot{ }^{[62]}$ The results confirmed that the microcapsules are capable of application in hot mix asphalt. Figure 16a shows that fine aggregates mixed with bitumen, which asphalt binder is marked with an arrow. $\mathrm{Su}$ et al. ${ }^{[61]}$ also proved that compatibility of microcapsules with bitumen performed well so that microcracks were not generated by microcapsules departing from the asphalt mixtures, which means addition of microcapsules will not affect the performance of asphalt. Figure 16b shows a fluorescence microscope morphology of microcapsules in asphalt binder. The surface of microcapsules is completely covered by asphalt binder and a fusion of microcapsules and bitumen can also be found. It can also be seen that rupture was not generated at the shell surfaces. The microcapsules were survived from agitation in the molten asphalt. Similar results have been reported in other works. ${ }^{[63]}$

To examine the microcapsules survival rate, $\mathrm{Su}$ et al. ${ }^{[60]}$ used a piece of asphalt which was peeled from an asphalt sample and heated to melt state under temperatures of 180 and $200^{\circ} \mathrm{C}$. Then melting bitumen without aggregates was spread on a microscope slide. Figure 17a,b shows the images of microcapsules in melting bitumen from asphalt samples (MB-3) under the temperature of $180{ }^{\circ} \mathrm{C}$. The microcapsules are keeping an intact globe shape. Even under temperature of $200^{\circ} \mathrm{C}$, as Figure $17 \mathrm{c}-\mathrm{e}$ shows, the microcapsules still keep their integrity without premature rapture. It indicates that the microcapsules resisted high temperature and strong squeeze during the asphalt samples production process. It is in agreement with the previous conclusions based on microcapsules in pure bitumen. ${ }^{[62]}$

\subsubsection{Distribution of Microcapsules in Asphalt Binder}

When applied in asphalt, agglomeration of microcapsules should be avoided since it may greatly influence the healing effect. ${ }^{[64]}$ Figure 18 shows the in situ fluorescence microscope
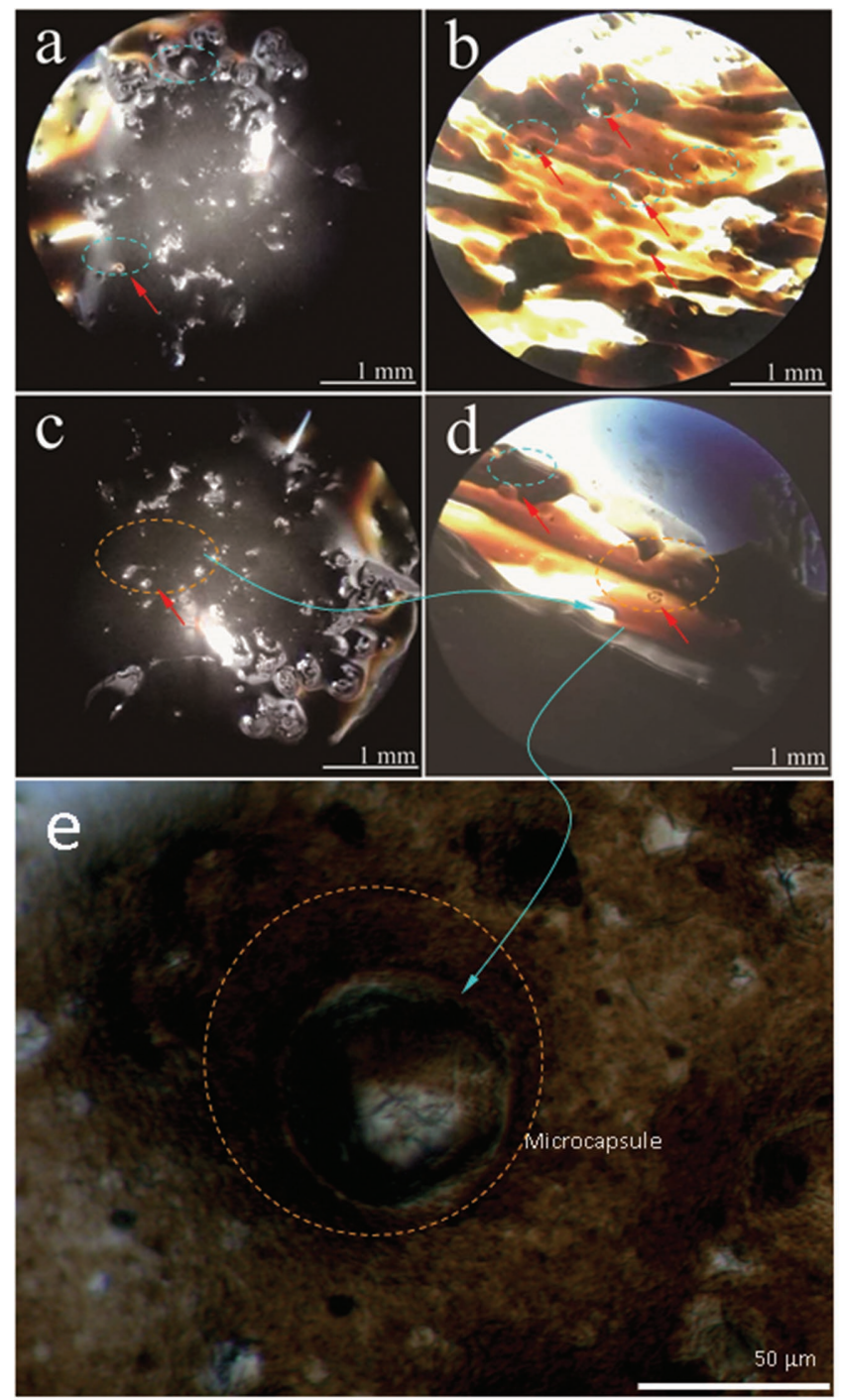

Figure 17. Optical morphologies of microcapsules in melting bitumen peeled from asphalt samples (MB-3) under high temperature; a,b) $180^{\circ} \mathrm{C}$ and c-e) $200^{\circ} \mathrm{C}$. Reproduced with permission. ${ }^{[60]}$ Copyright 2012, Elsevier Ltd. 

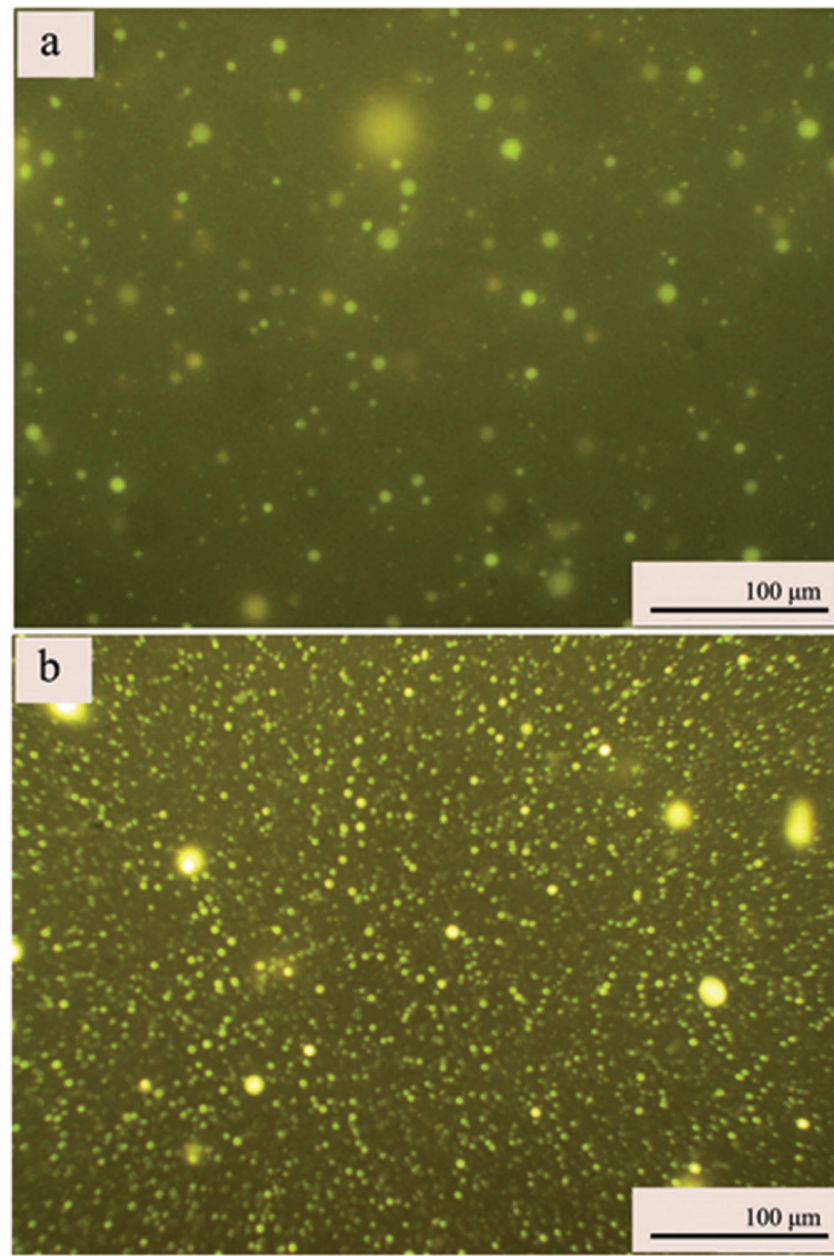

Figure 18. In situ observation of microcapsules dispersing in asphalt binder by a fluorescence microscope: morphologies of a) MB-3 and b) MB-7. Reproduced with permission. ${ }^{[60]}$ Copyright 2012, Elsevier Ltd.

morphologies of microcapsules dispersing in asphalt samples of MB-3 and MB-7. The microcapsules disperse in asphalt binders homogenously without adhesion. The shells of these microcapsules have an inorganic/organic composite structure; the electrostatic interaction between particles does not increase agglomeration.

Comparing Figure 18a and Figure 18b, increase in microcapsules content (3-7\%) also does not affect the dispersion of microcapsules. When the asphalt binder gets aged, the generated microcracks will break microcapsules and release the oily rejuvenator. If the microcapsules are not well dispersed, the healing effect will be limited.

Su et al. ${ }^{[60]}$ used X-ray computed tomography (XCT) to investigate the dispersion of microcapsules in asphalt. Since the shell has inorganic nano-CaCO3, the shape of microcapsules can be identified due to the density difference. Figure 19a shows an image of X-ray scanning of XCT instrument. Figure 19b shows an image of the bitumen/microcapsules samples with cylindrical shape (3.0 wt\%, microcapsules). Computed tomography (CT) scan is nondestructive test which allows the user to observe the inside of an object using computer-processed combinations of many X-ray image slices.
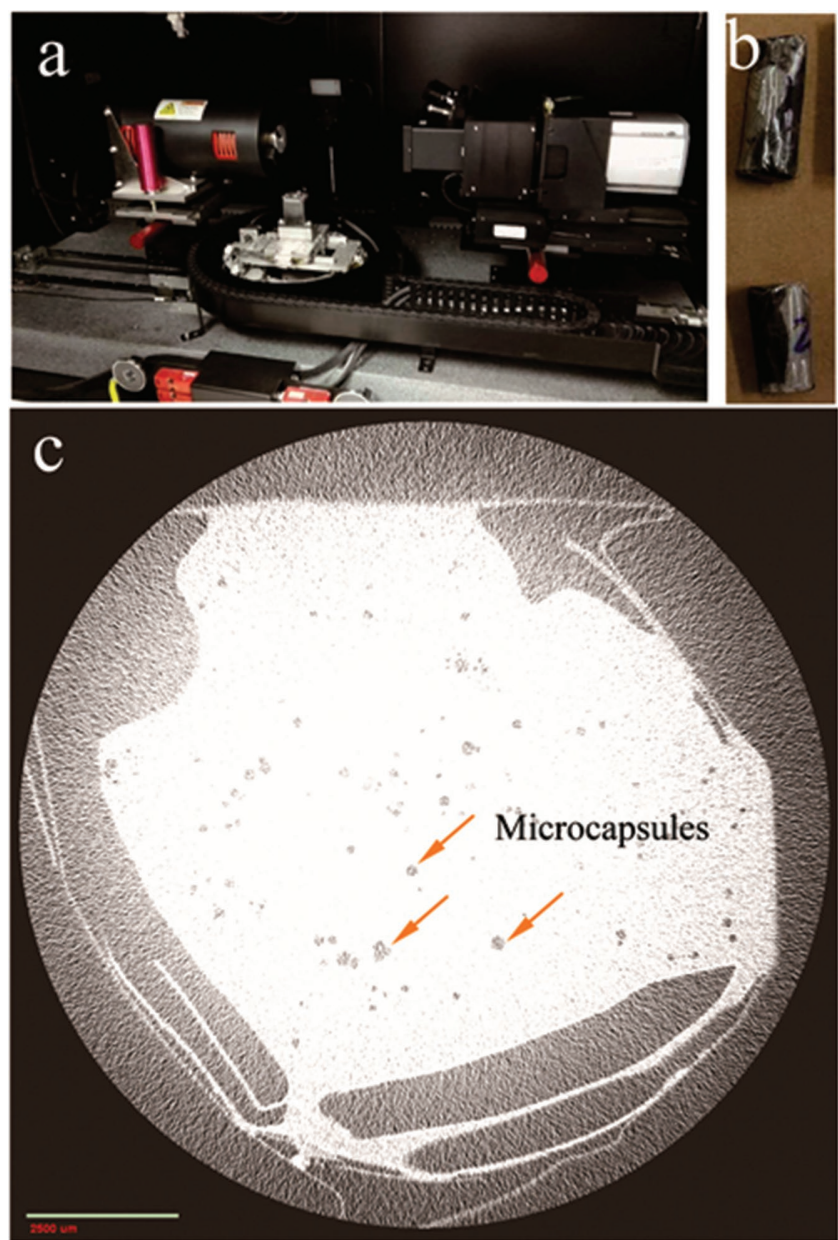

Figure 19. XCT investigation of microcapsules in pure bitumen. a) A photography of X-ray scanning part of XCT instrument, b) a photograph of testing microcapsules/bitumen samples with cylindrical shape $(3.0 \mathrm{wt} \%$, microcapsules), and c) XCT image of microcapsules dispersing in pure bitumen. Reproduced with permission. ${ }^{[60]}$ Copyright 2012, Elsevier Ltd.

These slices can be collected from different angles of specific areas of a scanned object. Figure 19c shows a typical tomographic slice of bitumen/microcapsules sample. The global shape of microcapsules can be clearly identified and microcapsules are found homogenously dispersed in asphalt binder. It can also be seen that the microcapsules were covered with inorganically particles due to the density difference.

$\mathrm{Su}$ et $\mathrm{al}^{[60]}$ also investigated the influence of aggregate on the distribution of microcapsules. Figure 20a shows a XCT slice of microcapsules dispersing in asphalt sample (BM-7) with a microcrack. Figure 20b illustrates the 3D-XCT image of asphalt sample (BM-7). It shows that the microcapsules have a full range distribution in asphalt which is important for effective crack healing.

The mechanism of self-healing of asphalt using microcapsules is clear that oily rejuvenator flow out from microcapsules and fill the whole microcrack through capillarity. ${ }^{[64]}$ As microcapsules are homogeneously distributed, the encapsulated rejuvenator is able to wet the surface of microcracks. The homogeneous dispersion of microcapsules also will help to disperse the rejuvenator to each damage sites. ${ }^{[64]}$ 

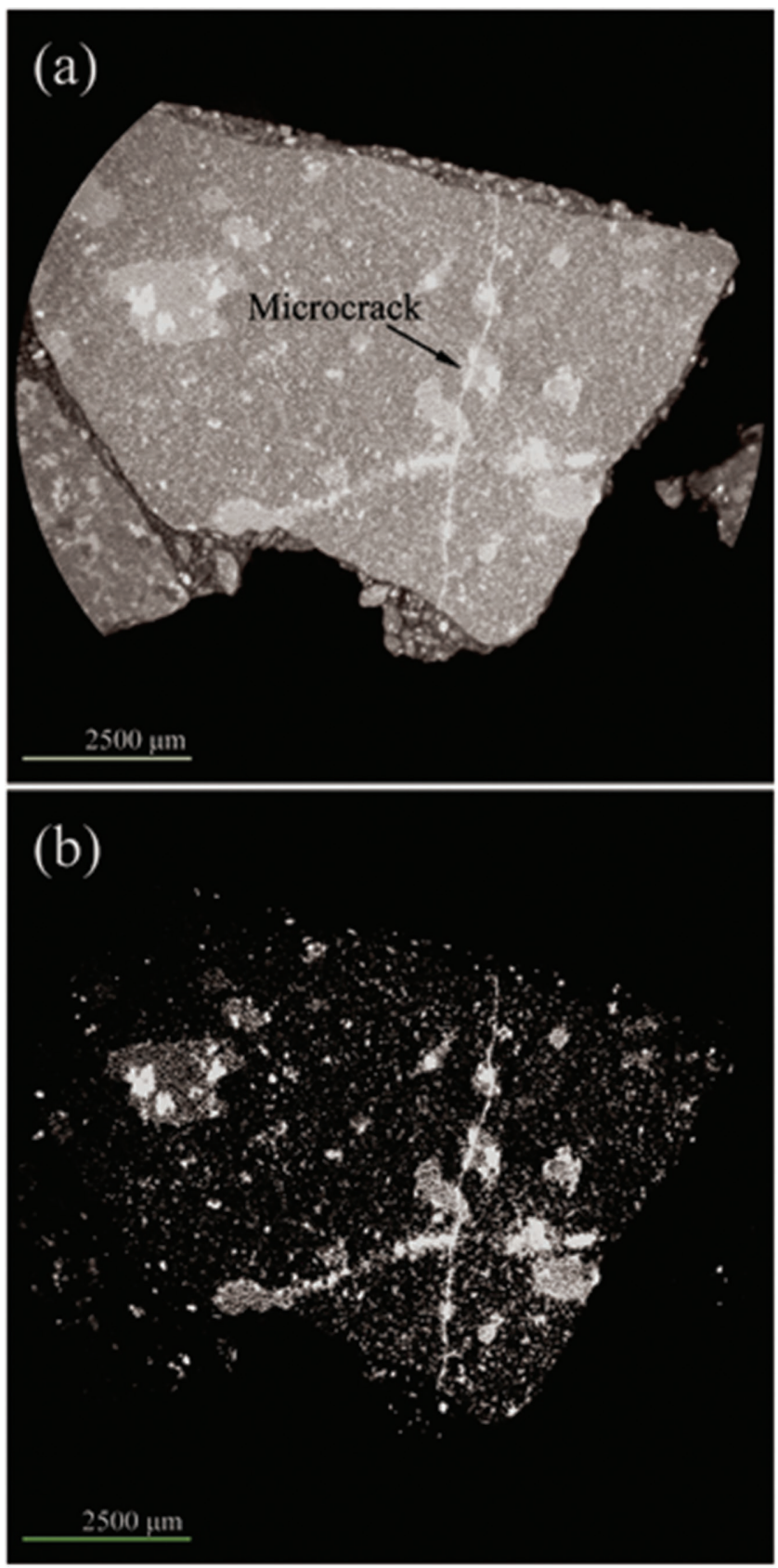

Figure 20. XCT images of microcapsules in asphalt binder (BM-7). a) A XCT slice of microcapsules dispersing in asphalt sample; b) a 3D image of microcapsules dispersing in asphalt sample. Reproduced with permission. ${ }^{[60]}$ Copyright 2012, Elsevier Ltd.

\subsubsection{Thermal Stability of Microcapsules in Asphalt}

The initial decomposition temperature of microcapsules was affected by core/shell ratio, morphology and shell material dropping speed. ${ }^{[18]} \mathrm{Su}$ et al. ${ }^{[60]}$ showed that the microcapsules with nano- $\mathrm{CaCO}_{3} /$ polymer shells are able to survive in 180 $200{ }^{\circ} \mathrm{C}$ bitumen. Although microcapsules are able to survive the asphalt mixing and production process, it still needs to prove that microcapsules can resist some extreme conditions. Asphalt in the field conditions withstands the external temperature
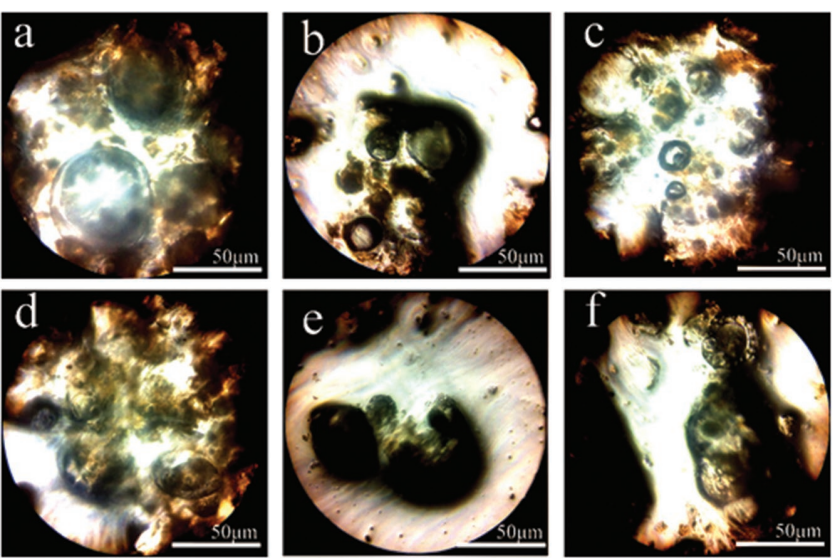

Figure 21. Morphologies of microcapsules in asphalt sample (MB-7) under various temperatures. a) $100^{\circ} \mathrm{C}$, b) $140{ }^{\circ} \mathrm{C}$, c) $180^{\circ} \mathrm{C}$, d) $220^{\circ} \mathrm{C}$, and e,f) $260^{\circ} \mathrm{C}$. Reproduced with permission. ${ }^{[60]}$ Copyright 2012, Elsevier Ltd.

changes. The temperature change cycles may damage the shell material and break microcapsules. This will significantly reduce the healing efficiency of microcapsule.

A fast heating process was applied to simulate a thermal shock of microcapsules first. An asphalt sample was placed in a temperature controlled oven to increase the temperature from room temperature to $200{ }^{\circ} \mathrm{C}$ at a rate of $5{ }^{\circ} \mathrm{C} \mathrm{min}^{-1}$. Then fluorescence microscope was used to observe the presence of microcapsules in asphalt binder under various temperatures. In Figure 21, morphologies of microcapsules in asphalt sample (MB-7) were shown under various temperatures of 100, 140, 180,220 , and $260^{\circ} \mathrm{C}$, respectively. In Figure $21 \mathrm{a}-\mathrm{d}$, it can be seen that the microcapsules keep their original shape without rapture. The possible reason is that the bitumen in asphalt binders does not create enough interior stress to break microcapsules. At the same time, the shells of microcapsules have the capability of resisting to a high temperature up to $180^{\circ} \mathrm{C}$, when temperature reaches at $220{ }^{\circ} \mathrm{C}$, rejuvenator has been released from the rapture microcapsules as shown in Figure 21e,f. ${ }^{[60]}$

$\mathrm{Su}$ et al. ${ }^{[60]}$ used a simulation method to investigate the thermal stability of microcapsules in asphalt binder under an alternating temperature process. Asphalt sample (MB-7) was heated to $50^{\circ} \mathrm{C}$ and then cooling down to $-10^{\circ} \mathrm{C}$ with the rate of $2{ }^{\circ} \mathrm{C} \mathrm{min}{ }^{-1}$. This process was repeated $50-100$ times. After that, a piece of sample was peeled off and heated to $150{ }^{\circ} \mathrm{C}$, then the melting bitumen was evenly distributed on glass and observed by a fluorescence microscope. In Figure 22a, microcapsules still compact particles without rapture dispersing in bitumen. It means that they resist the alternating temperature process repeated for 50 times. With an alternating temperature process repeated for 70 times, as show Figure 22b, it can be found that the particles are brighter and their diameter are increased. It might be because of the rejuvenator penetrating into asphalt binder. When an alternating temperature process repeated for 100 times, it can be seen the release trace of rejuvenator in Figure 22c. Some microcapsules may have been reputed by the thermal action. It needs to be mentioned that self-healing microcapsules may be broken at different conditions, which will supply a continuous rejuvenator into asphalt 

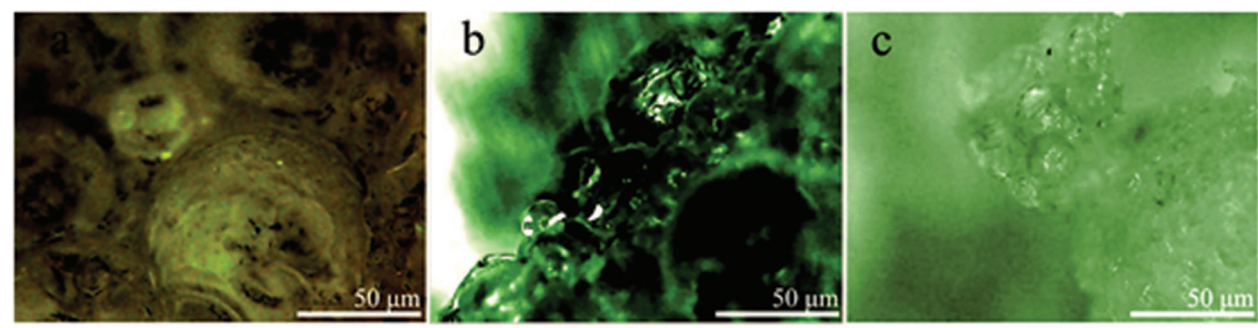

Figure 22. Fluorescence microscope morphologies of microcapsules in asphalt binders (MB-7) with a thermal treatment process repeated for different times: a) 50 , b) 70 , and c) 100 times. One temperature change cycle: heated to $50{ }^{\circ} \mathrm{C}$ with a rate of $2{ }^{\circ} \mathrm{C} \mathrm{min}-1$ and keeping for $10 \mathrm{~min}$, and then decreased the temperature to $-10^{\circ} \mathrm{C}$ at a rate of $2{ }^{\circ} \mathrm{C} \mathrm{min}^{-1}$. Reproduced with permission. ${ }^{[60]}$ Copyright 2012, Elsevier Ltd.

binder during the aging process. This Simulated environmental changes implied that microcapsules can survive in asphalt under temperature changes without rapture.

Microcapsules encapsulating rejuvenator can be used to enhance the self-healing capability of asphalt. Based on the world's first self-healing asphalt pavement using microcapsules, the states of these microcapsules in asphalt binders were investigated systematically in order to prove the compactability of microcapsules in asphalt. ${ }^{60]}$

\subsection{Calcium Alginate Capsules}

\subsubsection{Sodium Alginate and Its Encapsulation Potential}

The chemical compounds used in the production of polymeric microcapsules, such as melamine-formaldehyde, ${ }^{[65]}$ in large quantities could pose an environmental threat via leaching. The encapsulation of rejuvenator with alginate is explored as a solution to these problems.

Alginates are comprising of (1-4) linked units of $\alpha$-D-mannuronate $(\mathrm{G})$ and $\beta$-L-guluronate $(\mathrm{M})$ at different proportions and different distributions within the chains. ${ }^{[66]}$ The behaviors of alginate materials are largely determined by the G/M composition and sequence of the uronic acids. The chemical formula for sodium alginate is $\mathrm{C}_{6} \mathrm{H}_{7} \mathrm{O}_{6} \mathrm{Na}$ and its structural is shown in Figure 23.

\subsubsection{Application of Alginate in Self-Healing Material}

Alginates are widely existed in the nature which can be found in brown algae and can also be found in metabolic products of bacteria, e.g., pseudomonas and azotobacter. ${ }^{[67-69]}$
Currently, alginates are applied in various fields including food additives, gelling agents, wound dressings, and for drug delivery. ${ }^{[70-72]}$ Currently the alginate has been successfully investigated for its use in the field of material selfhealing technology. It has been used for the encapsulation of i) bacteria in microcapsules for concrete healing ${ }^{[73]}$ and ii) healing agent (solvents) for thermoplastic composite material healing. ${ }^{[74-76]}$ Advantages of Low price and environmental friendly provide alginates a bright prospect for the application in self-healing materials.

The encapsulation mechanism of alginate is described in Figure 24: when dissolved in liquid solution, doubly charged ions $(\mathrm{Ca} 2+)$ can bind two different alginate strands simultaneously by replacing positively charged sodium ions $(\mathrm{Na}+)$ thereby cross-linking and solidifying the solution. ${ }^{[7]}$

\subsubsection{Calcium Alginate Capsules Production Process}

Based on the alginate encapsulation mechanism, $\mathrm{Xu}$ et al.[20,78] successfully encapsulated asphalt rejuvenator with calcium alginate capsules. To produce the calcium alginate capsules, $6 \mathrm{wt} \%$ sodium alginate in deionized was prepared. At the same time, 2.5 wt $\%$ solution of poly(ethylene-alt-maleic-anhydride) (PEMA) was mixed with the rejuvenator with ratio of $40 \%$ PEMA and $60 \%$ healing agent to make a healing agent solution. After that, the sodium alginate solution and healing agent solution were mixed by the alginate/rejuvenator ration of 30/70 for $30 \mathrm{~s}$ at the stirring rate of $100 \mathrm{rpm}$. Subsequently, air bubbles were ejected out of the blend by exposing the blend to vacuum environment for $30 \mathrm{~min}$. Then the blend was pumped through a needle and the capsule beads were dropped into the $\mathrm{CaCl}_{2}$ solution. After drying in oven, the calcium alginate capsules are prepared.

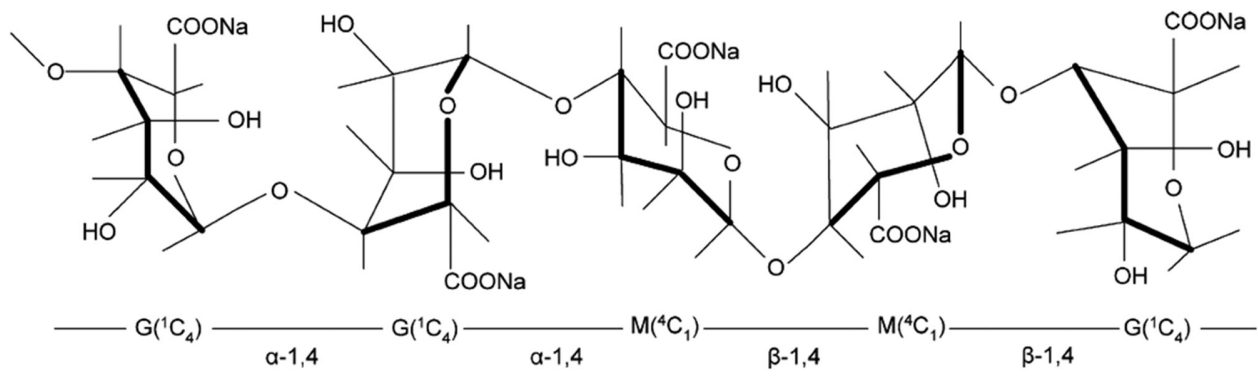

Figure 23. Structural formula of sodium alginate. Reproduced with permission. ${ }^{[19]}$ Copyright 2016, IOP Publishing Ltd. 


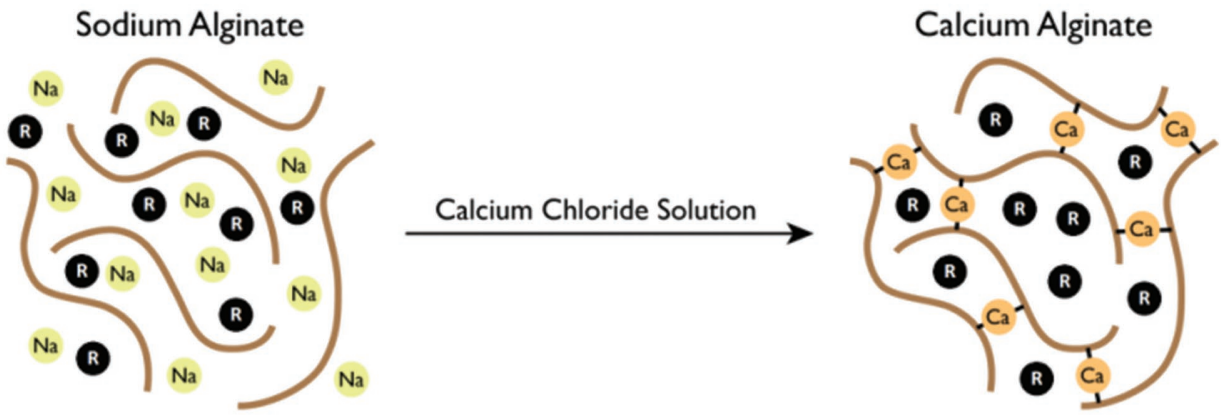

Figure 24. Encapsulation of rejuvenator with calcium alginate cross-linking. Reproduced with permission. ${ }^{[20]}$ Copyright 2018, Elsevier Ltd.

\subsubsection{Capsule Characterization}

$\mathrm{Xu}$ et al. used microscopy to characterize the morphology of calcium alginate capsules. Figure 25a shows the microscopic image of a calcium alginate capsule. The encapsulated rejuvenator makes the capsule presented in dark color, and these capsules have a uniform diameter of $1.95 \mathrm{~mm}$. Figure 25b shows the released rejuvenator from a crashed capsule. Figure $25 \mathrm{c}$ shows that the outer layer of capsule was surrounded by a dense calcium alginate cross-linking shell, and small rejuvenator droplets were distributed within the porous structure inside of the capsule. This structure allows rejuvenator to leak out and heal the damage site when crack reaches capsules. The rejuvenator content of a capsule is $56 \%$ by volume, which can be quantified by cumulating pixels in the X-ray computed tomography images (Figure 26).

Capsules thermal and mechanical resistances were investigated using the thermogravimetric analysis (TGA) and microcompressive tests. Figure 27a shows the thermogravimetric analysis results for the capsules. In the test, the capsules' weight loss was less than $1 \%$ before $100^{\circ} \mathrm{C}$. After $100^{\circ} \mathrm{C}$, the weight loss increased with temperature. This weight loss corresponds to the residual water evaporation from the calcium alginate shell material. At $160{ }^{\circ} \mathrm{C}$ which is regarded as the asphalt mixing temperature, the total weight loss of capsules reached $3.8 \%$. It indicates that except dehydration, there is no further degradation on capsules under $160{ }^{\circ} \mathrm{C}$. It indicates that the calcium alginate capsules are capable of surviving the asphalt mixing temperature of $140-160{ }^{\circ} \mathrm{C}$. Figure $27 \mathrm{~b}$ shows the compressive testing results for capsules cured with different temperatures. The compressive strength decreased with an increasing of curing temperature ranging from -20 to $160^{\circ} \mathrm{C}$. When cured under temperature between -20 and $100{ }^{\circ} \mathrm{C}$, capsules show similar compressive strength around $12 \mathrm{MPa}$ and the compressive behaviors are relatively stable as capsules cured with different temperatures. However, as curing temperature exceeded $100{ }^{\circ} \mathrm{C}$, the compressive strength of capsules decreased, which might due to the dehydration of the alginate gel which results in degradation of some calcium alginate chains. At the curing temperature of $160{ }^{\circ} \mathrm{C}$, the lowest compressive strength in the curve remains $3.27 \mathrm{MPa}$ which is higher than the stress during both asphalt mixing and cyclic loading of service life. ${ }^{[79]}$ Hence, the capsules are expected to survive asphalt mixing and vehical loadings in the service life.

\subsubsection{Application in Asphalt Mastic}

In the research, $\mathrm{Xu}$ et al. showed a cross-section interface of a cracked asphalt mastic beam, as shown in Figure 28. Figure 28b shows the cracking interface and Figure 28c shows the magnified interface image. Figure $28 \mathrm{~b}$ illustrates that broken capsules distributed throughout the cracking interface of the beam. These capsules were successfully fractured by the propagation of central crack in the three-point-bending (3PB) test. The presence of capsules throughout the crack interface proves that the adhesion between capsules and asphalt binder is strong, which means that cracks are able to propagate across the depth of the capsules instead of circumventing them to trigger the release of rejuvenator as experienced with polymeric capsules. ${ }^{[80]}$

Figure 29 summarizes the bending strength of asphalt mastic beams in $3 \mathrm{~PB}$ tests. It indicates that the presence of these capsules inside the mastic beams provides a reinforcing effect which increases the bending strength of asphalt mastic
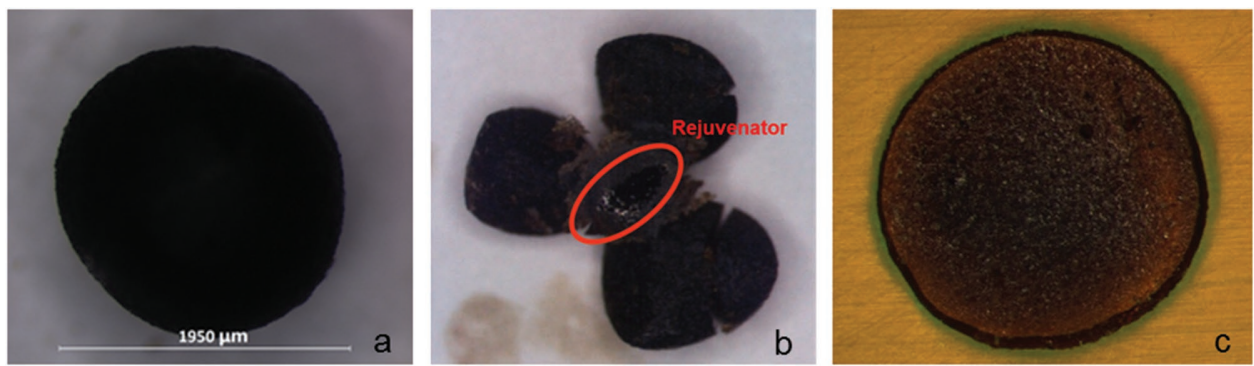

Figure 25. a) Microscopic image of calcium alginate capsule, b) rejuvenator released from crashed capsule, and c) cross-sectional area of capsule. Reproduced with permission. ${ }^{[20]}$ Copyright 2018, Elsevier Ltd. 

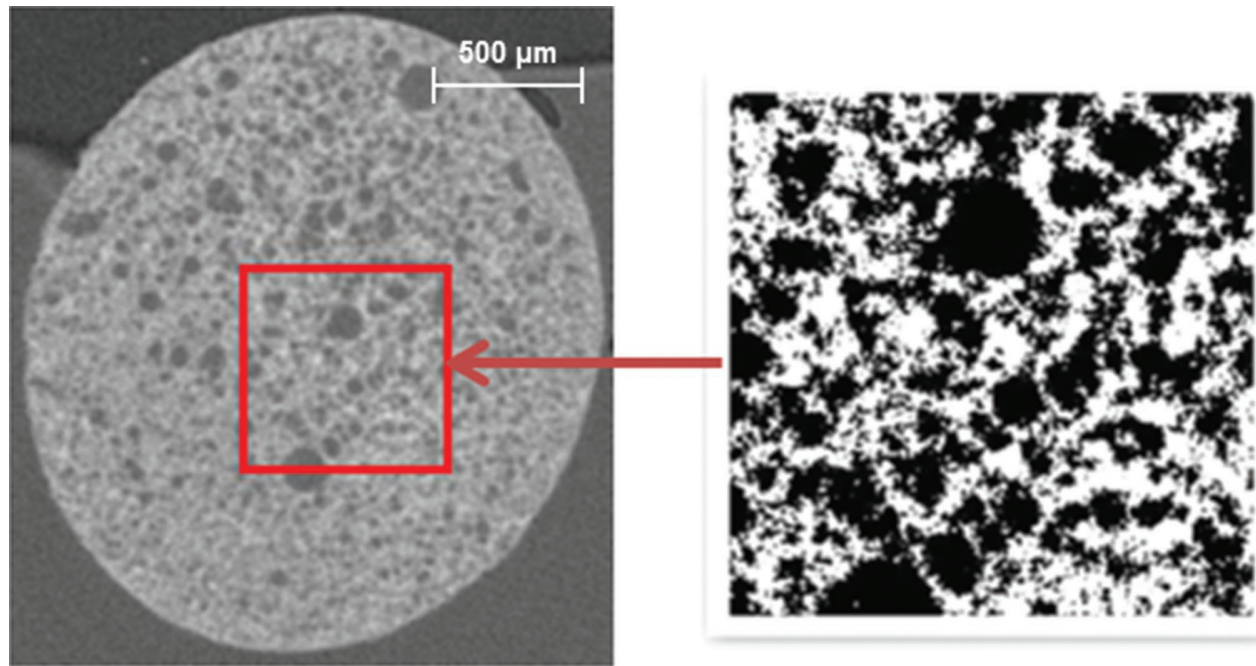

Figure 26. X-ray tomography image. Reproduced with permission. ${ }^{[20]}$ Copyright 2018, Elsevier Ltd.

beams. This reinforcing effect is proportional to the amount of applied capsules in asphalt mastic beams.

$\mathrm{Xu}$ et al. ${ }^{[20]}$ used a monotonic 3PB loading and healing program (Figure 30a) to evaluate the healing efficiency of the calcium alginate capsules healing system. Hence, the healing effect can be evaluated by the strength recovery which is quantified by the ratio between the strength of each healing stage and its original bending strength. The healing efficiency of the capsules was investigated with the 3 PB testing and healing program as shown in Figure 30b. The intrinsic healing capacity of asphalt allowed the asphalt mastic beams without capsules healed, $75.7 \%$ of the original strength in the first healing and $50.0 \%$ in the second healing. While with capsules, this healing effect is improved significantly. By adding $2 \%$ capsules, the healing index could reach $90.1 \%$ after the first healing and $76.4 \%$ after second. Nethertheless, addition of $4 \%$ capsules showed less healing effect than $2 \%$, for which healing index is $81.7 \%$ and $73.2 \%$ for the two healing stages.

$\mathrm{Xu}$ et al. ${ }^{[20,78]}$ demonstrated that addition of calcium alginate capsules with encapsulated rejuvenator significantly increases the healing efficiency of asphalt mastic. To achieve an optimum healing effect in asphalt, more researches are needed. Calcium alginate capsules are capable of rejuvenator encapsulation and damage site healing in asphalt mastic mix. These capsules show huge potential for the application in self-healing asphalt.

\subsection{Compartmented Calcium Alginate Fibers}

Researcher, as shown above, ${ }^{[50,51]}$ demonstrated capsules containing rejuvenator can be produced and these capsules are able to survive the asphalt production process. The addition of large quantities of microcapsules into the asphalt mix can reduce the quality of the pavement which itself may cause premature pavement failure. Garcia et al. ${ }^{[46]}$ and Sun et al. ${ }^{[81]}$ reported that application of microcapsules may reduce the stiffness of asphalt. They explained that it is releasing of rejuvenator that softens the asphalt binder. However, it is well documented $^{[57]}$ that deformation in the asphalt mix is caused by sand granulates. It is possible that due to the inclusion of microcapsules, sand like particles caused increased asphalt mix deformation, i.e., rutting. The encapsulation of a rejuvenator within compartmented calcium alginate microfibers offers the potential to overcome these problems. ${ }^{[82]}$

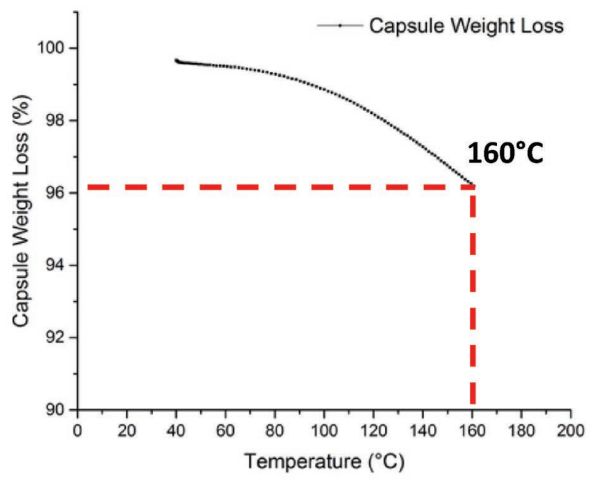

a)

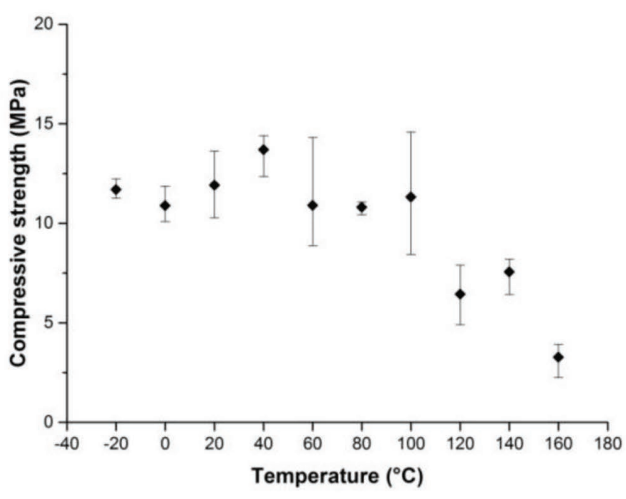

b)

Figure 27. Calcium alginate capsules containing rejuvenator: a) TCA test results, b) compressive strength versus curing temperature. Reproduced with permission. ${ }^{[20]}$ Copyright 2018, Elsevier Ltd. 

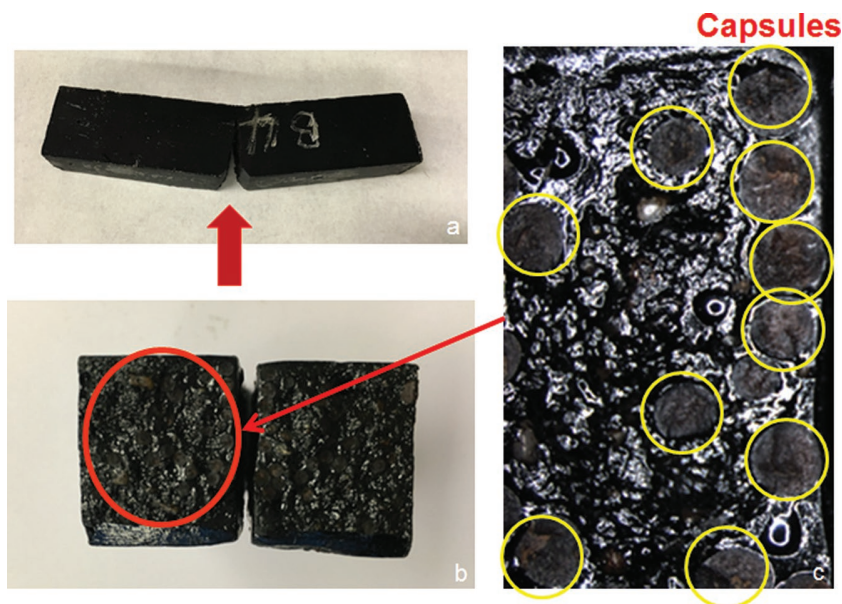

Figure 28. Asphalt mastic beam: a) Cracked sample, b) cracking interface, and c) magnified interface image. Reproduced with permission. ${ }^{[20]}$ Copyright 2018, Elsevier Ltd.

The compartmented alginate fiber encapsulating bitumen rejuvenator is a unique self-healing technology for asphalt pavements, whereby the encapsulated rejuvenator within the asphalt mix is used as the healing catalyst. The principle underpinning this technology is that when microcracks begin to form within the pavement, they encounter a microcapsule. The fracture energy at the crack-tip will open the capsule, thereby releasing the rejuvenator. The rejuvenator then diffuses with the asphalt binder to seal the crack, preventing its further propagation. Figure 31 illustrates the compartmented alginate fiber encapsulating bitumen rejuvenator self-healing concept.

\subsubsection{Application in Asphalt Mastic}

Figure 31 shows the compartmented fibers with multiple compartments encapsulating bitumen rejuvenator. These fibres

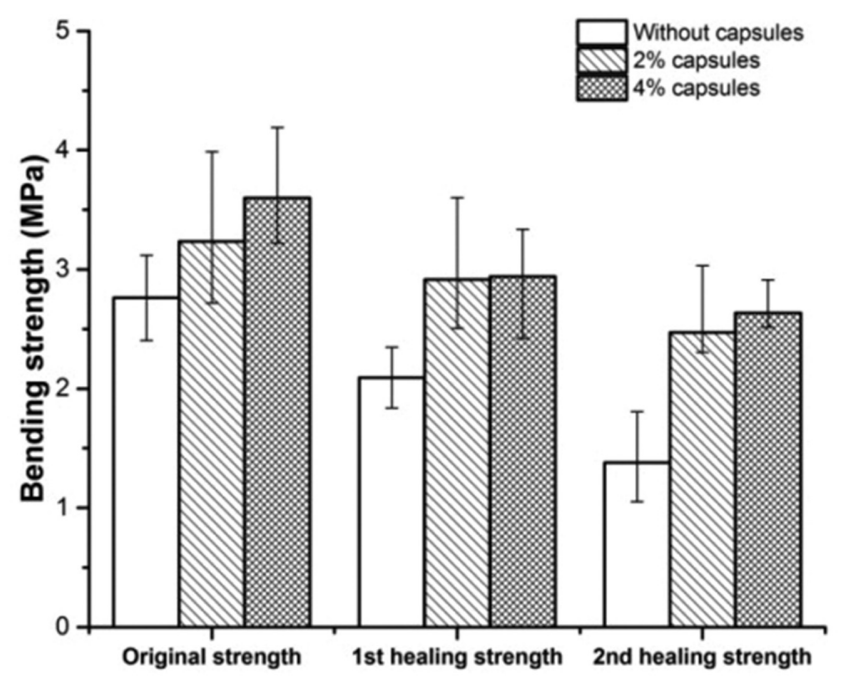

Figure 29. 3 PB bending strength of asphalt mastic beams. Reproduced with permission. ${ }^{[20]}$ Copyright 2018, Elsevier Ltd. were spun from a blend of rejuvenator suspended in a water solution of alginate. To this aim, $6 \mathrm{wt} \%$ solution of sodium alginate in deionized water was prepared. At the same time, $2.5 \mathrm{wt} \%$ PEMA polymeric surfactant solution was prepared by dissolving the copolymer in water at $70{ }^{\circ} \mathrm{C}$ and mixing it for $60 \mathrm{~min}$. After the PEMA has been dissolved in the water, it was allowed to cool to room temperature $\left(20 \pm 2{ }^{\circ} \mathrm{C}\right)$ and was added to the rejuvenator in proportion of $40 \%$ PEMA and $60 \%$ rejuvenator, forming a healing agent solution. Sodium alginate and PEMA/rejuvenator solutions were then combined in and optimum rejuvenator/alginate 70:30 proportion. The solution was mixed at $200 \mathrm{rpm}$ for $60 \mathrm{s.}{ }^{[50,74]}$

The blend was then spun with a plunger-based lab scale wet spinning line in a conventional wet spinning process ${ }^{[74,75]}$ to form the rejuvenator-encapsulated compartmented fibers. A spinneret containing one capillary of $0.5 \mathrm{~mm}$ diameter and $1.5 \mathrm{~mm}$ length was used. The extrusion rate was $1.93 \mathrm{~cm}^{3} \mathrm{~min}^{-1}$ and the take up speed was $19.1 \mathrm{~m} \mathrm{~min}^{-1}$. The coagulation bath was $0.8 \mathrm{~m}$ long and contained a $0.45 \mathrm{M}$ solution of $\mathrm{CaCl}_{2} \cdot 6 \mathrm{H}_{2} \mathrm{O}$. More details on the fiber preparation and spinning process can be found elsewhere. ${ }^{[75]}$ Figure 32 shows an image of a compartmented alginate fiber encapsulating rejuvenator captured by optical microscope technique.

\subsubsection{Fiber Performance}

Figure 33a shows the results of the TGA of the fiber. The compartmented fibers lost $25 \%$ of their weight at $270{ }^{\circ} \mathrm{C}$, and a further weight loss of $9 \%$ during the asphalt mixing process (temperatures of $160^{\circ} \mathrm{C}$ ) most likely due to residual water evaporation from the calcium alginate. These results indicate that the alginate are able to resist the high temperatures during the asphalt mixing process. Figure $33 \mathrm{~b}$ shows the uniaxial tensile strength (UTS) versus temp. of the optimal (70:30) fibers, the results show to be at the lower end, in the range between 20 and $53 \mathrm{MPa}$ depending on the conditioning temperature. However, its linearity, small change in UTS across the thermal range, indicates the limited effect of temperature (high and low) on the fiber properties. These results indicate that the alginate fiber encapsulating rejuvenator can, in principle, resist the high processing temperatures of the asphalt mixing process. ${ }^{[19]}$

\subsubsection{Healing Efficiency}

Tabaković et al. showed that alginate fibers have great potential as self-healing technique for asphalt pavements, i.e., they can be inserted into the asphalt mastic mix (fibers can survive asphalt mixing and compaction process) and can increase asphalt mastic mix strength by $36 \%$. The optimum rejuvenator alginate ratio is $70: 30 .{ }^{[52]}$ However, the study showed that fibers have limited healing capacity. The fibers are effective in healing of microcracks, however, the system is less efficient in healing of large cracks. Figures 34 and 35 illustrate healing efficiency of an asphalt mortar mix with and without fibers. This was explained by low amount of rejuvenator contained in the mix, fiber-rejuvenator alginate ratio was 40:60, in order to initiate healing of the asphalt mix. Further study showed that with 

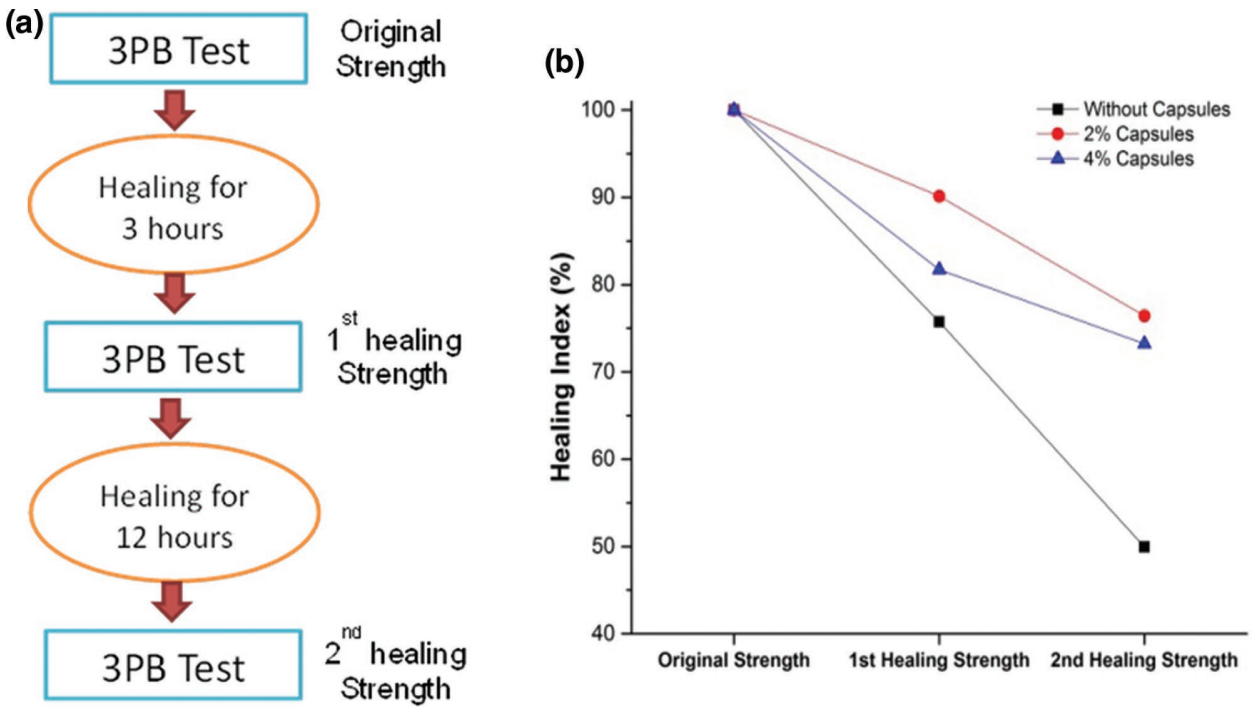

Figure 30. Healing efficiency study of asphalt mastic beams: a) testing and healing program; b) healing efficiency of asphalt mastic beams. Reproduced with permission. ${ }^{[20]}$ Copyright 2018, Elsevier Ltd.

increase of the rejuvenator alginate ratio in the fiber mix to 70:30 improved healing rate. ${ }^{[52]}$ Tabaković et al. ${ }^{[52]}$ also showed that higher amounts of fiber $10 \%$ volume of the mix could reduce healing capacity of the asphalt mix. Figure 36 shows that optimum amount of the fiber in the mix was $5 \%$ by volume of the constituents.

Tabaković et al. ${ }^{[83]}$ further demonstrated that optimum healing time for zeer open asfalt beton (ZOAB) mix using compartmented alginate fibers encapsulating rejuvenator is $20 \mathrm{~h}$. Figure 37 illustrates successful crack closure (healing) in an asphalt test specimen containing 5\% compartmented alginate fibers encapsulating the rejuvenator after $20 \mathrm{~h}$ of healing.

Figure 38 shows the crack propagation speed within semicircular bend (SCB) test sample at the initial test and after two healing stages. ${ }^{[83]}$ It is clear from the graph that the fiber mix experiences slower crack propagation. This could be due

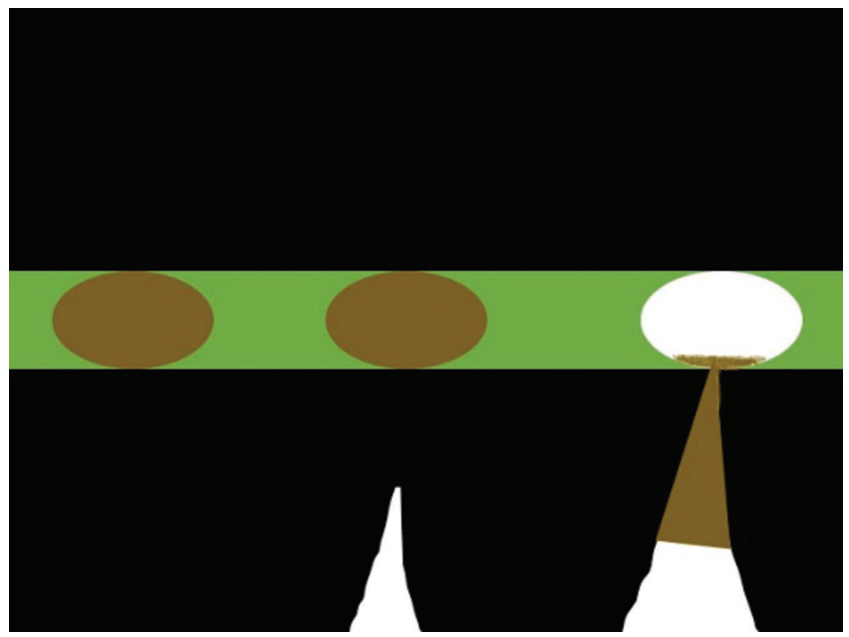

Figure 31. Compartmented alginate fibers encapsulating rejuvenator concept. to the softened binder and reduced fracture energy available for crack propagation. This result illustrates the benefits of the compartmented fiber encapsulating a rejuvenator mix in terms of crack propagation, where the rejuvenation (softening) of aged binder can reduce the brittleness of the aged binder, thereby reducing the energy available for crack propagation.

Tabaković et al. ${ }^{[83]}$ also studied healing performance of a ZOAB asphalt mix containing the fiber healing system subjected to the fatigue loading. Figure 39 shows the healing efficiency of the ZOAB control mix and fiber mix flexural stiffness $\left(S_{\text {mix }}\right)$. The results show a very close initial test performance (Figure 39 a). However, Figure 39b shows a higher stiffness recovery for the PA fiber mix after $20 \mathrm{~h}$ healing at $20{ }^{\circ} \mathrm{C}$. These results demonstrate the potential benefits of the PA mix containing compartmented alginate fibers encapsulating the rejuvenator.

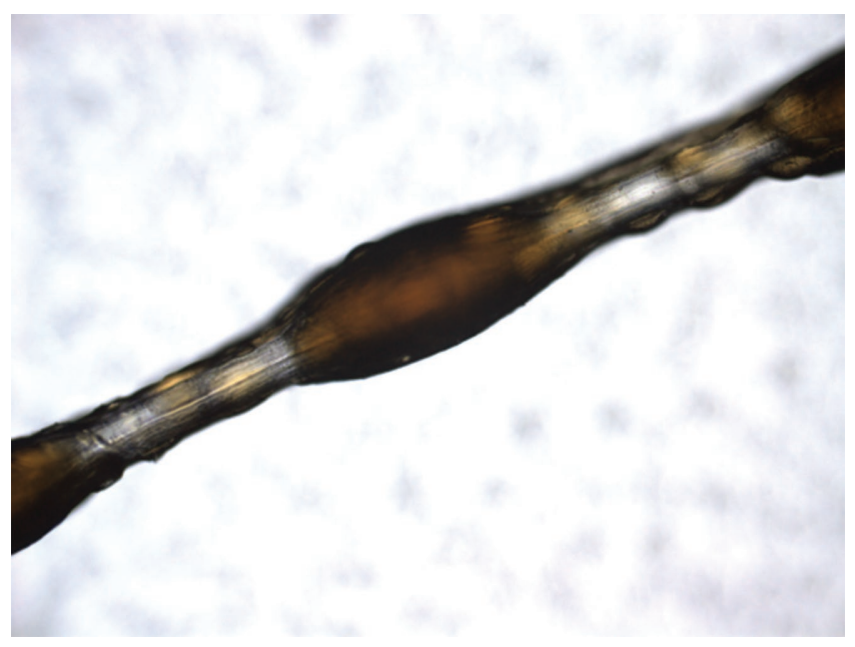

Figure 32. An image of a compartmented alginate fiber encapsulating rejuvenator captured by optical microscope. Plane polarized light imaging. Field of view is $\approx 3 \mathrm{~mm}$. Reproduced with permission. ${ }^{[19]}$ Copyright 2016, IOP Publishing Ltd. 

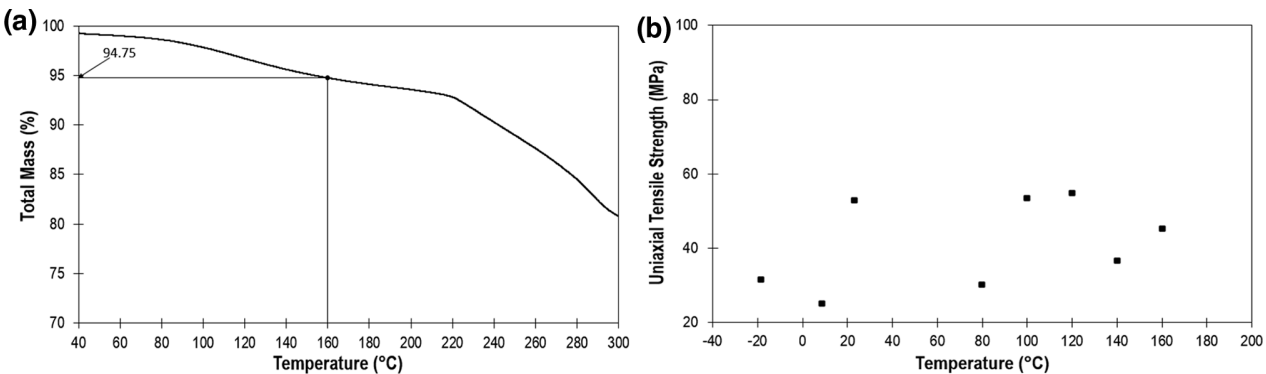

Figure 33. Sodium alginate compartmented fibers containing rejuvenator. a) TGA test results, b) uniaxial strength versus temperature. Reproduced with permission. ${ }^{[19]}$ Copyright 2016, IOP Publishing Ltd.
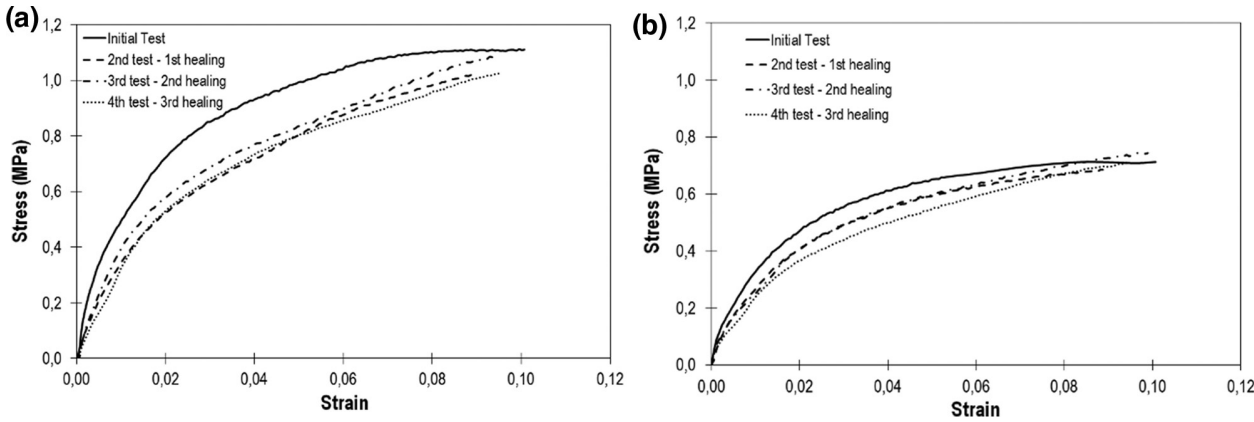

Figure 34. Typical $3 \mathrm{~PB}$ test load versus deflection plots for asphalt mastic mix at $20^{\circ} \mathrm{C}$, at varying healing stages: a) mix containing fibers, b) mix without fibers. Reproduced with permission. ${ }^{[19]}$ Copyright 2016, IOP Publishing Ltd.

Tabaković et al. demonstrated that fibers even with optimum fiber design and fiber content in the mix are still unable significantly to improve large damage (crack) repair properties. Nevertheless, study demonstrated that fibers contain a potential in healing microcracks within an asphalt mix.

\section{Vision on Future Development of Self-Healing Asphalt Pavements}

The key aim of the self-healing asphalt pavements is to develop asphalt pavement material that will be capable of healing itself without external intervention. Therefore, the ultimate objective for highway designers is to develop an asphalt pavement material that will heal itself. To achieve this, the self-healing processes happened within the asphalt pavement system should be able to self-assess. This would enable the material to continuously monitor the health of its structure and its materials, and respond in a manner that fulfills its functional requirements based on the danage. ${ }^{[84]}$

Tabaković and Schlangen ${ }^{[82]}$ stated that in order to develop a new generation of self-healing asphalt pavements, based on findings of currently available self-healing technologies, three specific working areas are identified that need particular effort.

\subsection{Development of Damage Sensing and Repair Triggering Elements}

For instance, signaling transport and activation of the healing mechanism, which means the sensory function has to be developed and extended with an active learning functionality, able to differentiate and to detect damage, to interpret the obtained information and to respond the damage information by triggering the healing action. These sensor elements should
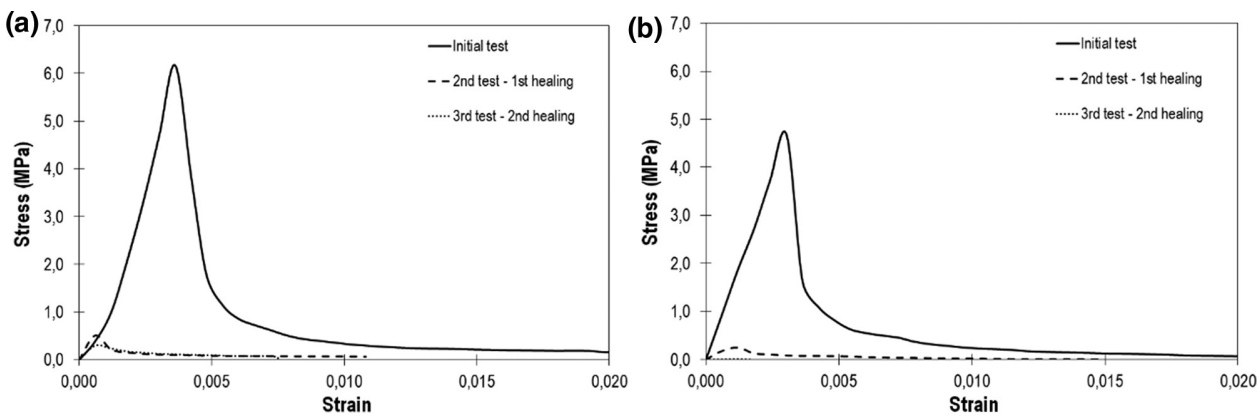

Figure 35. Typical $3 \mathrm{~PB}$ test load versus deflection plots for asphalt mastic mix at $-5^{\circ} \mathrm{C}$, at varying healing stages: a) mix containing fibers, b) mix without fibers. Reproduced with permission. ${ }^{[19]}$ Copyright 2016, IOP Publishing Ltd. 
(a)

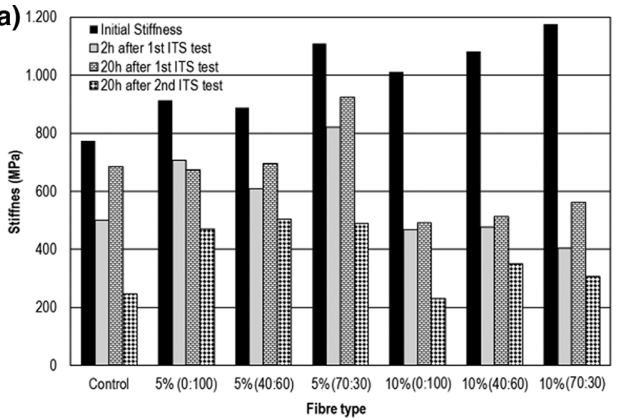

(b)

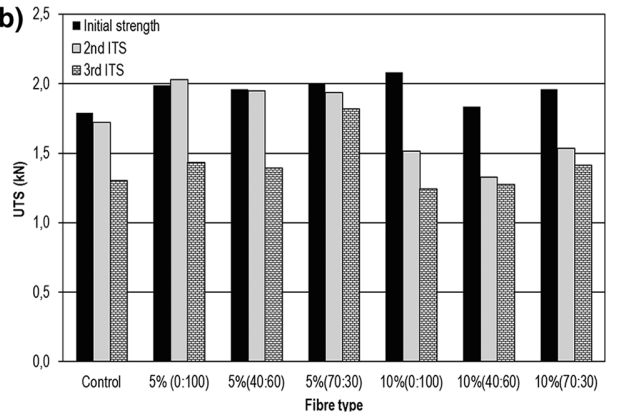

Figure 36. Healing efficiency of ZOAB mix containing varying amounts of fibers in the mix. a) Stiffness and b) tensile strength. Reproduced with permission. ${ }^{[83]}$ Copyright 2017, MDPI AG.

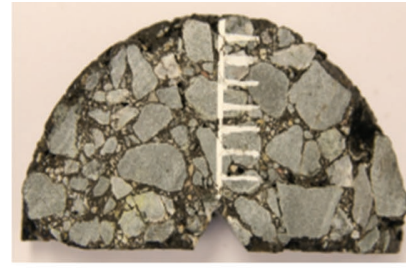

Before test

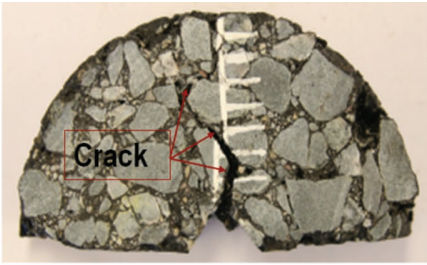

After test

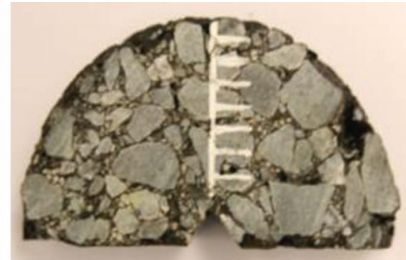

After $20^{\text {hrs }}$ healing

Figure 37. SCB test specimen crack closure/healing. Reproduced with permission. ${ }^{[83]}$ Copyright 2017, MDPI AG.

ideally be structural components of the pavement system and should not deteriorate the general functionality of the pavement system. The development of the sensory mechanism within the pavement system will allow for healing-on-demand action, such an action could be triggered by a fall in current/resistivity in the pavement system or by a concentration of stress, which will initiate the repair action while activating an initiator (healing agent or heating). The healing process would be activated in an instant without delay which would ensure (providing that external conditions are adequate, i.e., healing time and temperature) fast damage repair. Hence, the pavement material achieve self-healing.

\subsection{Development of Multiple Self-Healing Processes}

To date, only a limited number of self-healing mechanisms for asphalt pavements have been developed, such as the induction heating and rejuvenator encapsulation. In order to meet a pavement functional requirement, new self-healing mechanisms have to be developed and employed to cover a broader range of performance demands, such as healing/rest time. All three self-healing mechanisms presented in Section 2 require at least $4 \mathrm{~h}$ of rest time in order for binder mix to achieve full recovery. On busy highways this is difficult to expect. The self-healing times for asphalt pavement need to be improved. Another essential part of the self-healing mechanism in asphalt pavements is multihealing action. If a self-healing mechanism does not possess the multihealing ability, such as encapsulated rejuvenator, it makes pavement vulnerable to cracking after first repair, as it has no ability to stop and heal the damage. This will ultimately lead to asphalt pavement failure. This requirement of a self-healing mechanism is directly linked to the sensory/triggering mechanism. If a healing-on-demand can be achieved, repair action will be activated instantly reducing damage level and as such the demand on the healing system, such as microcapsules, and thus it will make it more efficient.

\subsection{Development of Self-Healing Assessment Mechanism for Autonomous Health Assessment of the Asphalt Pavement System and in Case of Damage Repair, to Quantify the Success of the Self-Healing Process}

To date, there has been only a limited understanding of quantification of the success of self-healing, mostly by measurement of mechanical performance, such as material strength. This requires on site pavement evaluation, or obtaining test samples from site and conduction laboratory material evaluation. This

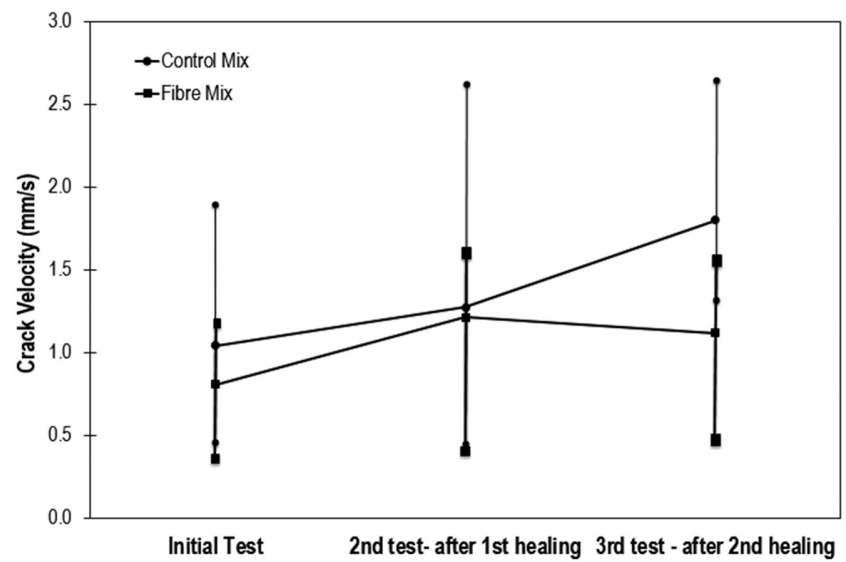

Figure 38. Crack speed. Reproduced with permission. ${ }^{[83]}$ Copyright 2017 , MDPI AG. 

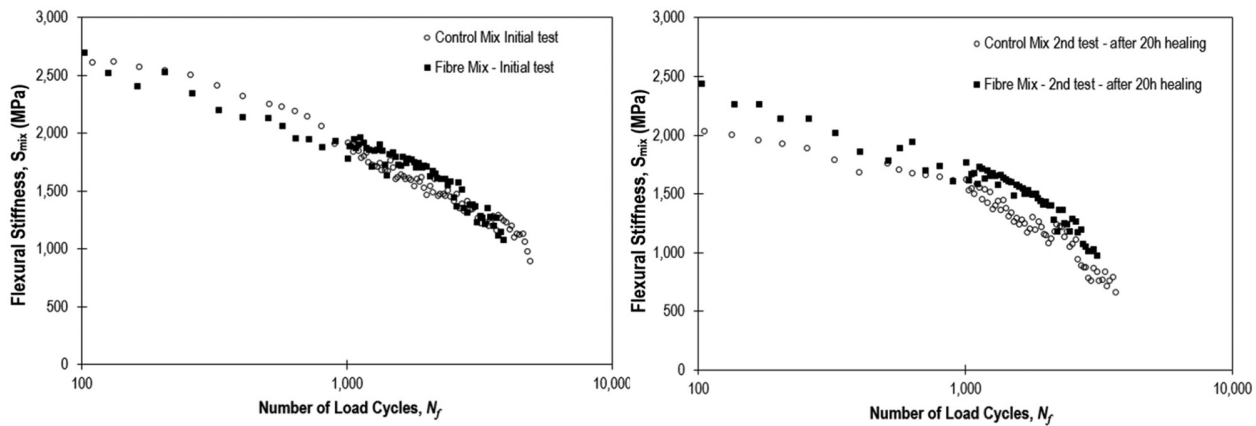

Figure 39. 4 PB results-healing efficiency of the fiber asphalt mix versus control asphalt mix. a) Initial test results. b) Test results after $20 \mathrm{~h}$ healing at $20^{\circ} \mathrm{C}$. Reproduced with permission. ${ }^{[83]}$ Copyright 2017, MDPI AG.

requires traffic control which could result in traffic delays and high financial and environmental costs. A mechanism for the autonomous assessment of asphalt pavement system health and the assessment of the self-healing process needs to be the focus of the future research in this field.

If these developments in the self-healing processes are met, then it will be possible to create a truly smart asphalt pavement system, which senses its internal state and external environment and responds in an appropriate manner to this information. The primary advantage of moving toward smart/self-healing technology is the potential cost benefit of condition-based maintenance strategies and the prospective lifespan that may be achieved for asphalt pavements materials, through in situ health management.

The potential benefits of self-healing asphalt technology in material performance, environmental and social benefits will undoubtedly stimulate interest for the wider use of selfhealing technology in asphalt pavement design and construction. However, for self-healing technology to become accepted as the industry standard, its superiority in the construction and maintenance of asphalt pavements must be demonstrated, as well as from functional perspective, from economic and environmental perspective.

\section{Conclusion}

As a built-in property of asphalt, self-healing capacity has great potential to prolong service life of asphalt pavements. To achieve efficient and effective healing in asphalt, innovative ideas including induction healing and capsule healing have shown significant effect in laboratory.

The asphalt induction healing system is very effective to promote the healing capacity of asphalt pavement especially the healing of microcracks. The induction healing system has been tested in the laboratory and validated in the field. Now, the technology is mature enough and waiting for the promotion from industry.

The capsule healing system is capable of cracking site repairing of asphalt pavement. The healing mechanisms include both crack healing and aged binder rejuvenation. Various encapsulation methods have been investigated in the laboratory. For a larger scale application of the capsule healing system, more field testing data need to be validated.
Incorporating self-healing technology in asphalt pavement not only contributes to a more sustainable road, but also solves environmental and economic problem by reducing the cost and pollutions during maintenance and production process. Development of self-healing technology for asphalt pavements will truly revolutionize asphalt pavement design. It will bring the concept of self-healing asphalt from idea to practice.

\section{Conflict of Interest}

The authors declare no conflict of interest.

\section{Keywords}

asphalt, capsules, induction healing, self-healing

Received: April 8, 2018

Revised: June 11, 2018

Published online: July 18, 2018

[1] P. Bazin, J. Saunier, presented at Intl. Conf. Struct. Design Asphalt Pavements, Ann Arbor, Michigan, August 1967.

[2] J. Qiu, Thesis, TU Delft, Delft University of Technology, Delft, 2012.

[3] D. Little, R. Lytton, D. Williams, C. Chen, Y. Kim, H. Lee, FHWA Final Report, 1998, p. 1.

[4] D. Williams, D. Little, R. Lytton, Y. Kim, Y. Kim, Microdamage Healing in Asphalt and Asphalt Concrete, Volume 2: Laboratory and Field Testing to Assess and Evaluate Microdamage and Microdamage Healing, Turner-Fairbank Highway Research Center, McLean, VA, USA 2001.

[5] Y. R. Kim, D. N. Little, F. C. Benson, J. Assoc. Asphalt Paving Technol. $1990,59,240$.

[6] A. Bhasin, D. N. Little, R. Bommavaram, K. Vasconcelos, Road Mater. Pavement Des. 2008, 9, 219.

[7] A. Bhasin, R. Bommavaram, M. L. Greenfield, D. N. Little, J. Mater. Civ. Eng. 2010, 23, 485.

[8] Y. Hou, L. Wang, T. Pauli, W. Sun, J. Mater. Civ. Eng. 2014, 27, 04014118.

[9] N. Tabatabaee, M. H. Shafiee, in 7th RILEM Int. Conf. Cracking in Pavements, Springer, Dordrecht 2012, pp. 869-878.

[10] Á. García, E. Schlangen, M. van de Ven, Q. Liu, Constr. Build. Mater. 2012, 31, 38. 
[11] Q. Liu, E. Schlangen, Á. García, M. van de Ven, Constr. Build. Mater. 2010, 24, 1207.

[12] Q. Liu, E. Schlangen, M. van de Ven, J. Mater. Civ. Eng. 2012, 25, 880.

[13] J. Gallego, M. A. del Val, V. Contreras, A. Páez, Constr. Build. Mater. 2013, 42, 1 .

[14] J. Norambuena-Contreras, A. Garcia, Mater. Des. 2016, 106, 404.

[15] T. Al-Mansoori, R. Micaelo, I. Artamendi, J. Norambuena-Contreras, A. Garcia, Constr. Build. Mater. 2017, 155, 1091.

[16] A. Garcia, J. Jelfs, C. J. Austin, Constr. Build. Mater. 2015, 101, 309.

[17] R. Micaelo, T. Al-Mansoori, A. Garcia, Constr. Build. Mater. 2016, 123, 734.

[18] J.-F. Su, J. Qiu, E. Schlangen, Polym. Degrad. Stab. 2013, 98, 1205.

[19] A. Tabaković, W. Post, D. Cantero, O. Copuroglu, S. Garcia, E. Schlangen, Smart Mater. Struct. 2016, 25, 084003

[20] S. Xu, A. Tabaković, X. Liu, E. Schlangen, Constr. Build. Mater. 2018, 169, 379.

[21] K. Chung, S. Lee, M. Park, P. Yoo, Y. Hong, J. Ind. Eng. Chem. 2015, $29,330$.

[22] R. C. Barrasa, V. B. López, C. M.-P. Montoliu, V. C. Ibáñez, J. Pedrajas, J. Santarén, Procedia - Soc. Behav. Sci. 2014, 162, 188.

[23] Q. Liu, E. Schlangen, M. F. van de Ven, G. van Bochove, J. van Montfort, in 7th RILEM Int. Conf. Cracking in Pavements, Springer, Dordrecht 2012, pp. 1081-1089.

[24] S. Salih, B. Gómez-Meijide, M. Aboufoul, A. Garcia, Constr. Build. Mater. 2018, 167, 716.

[25] J.-F. Su, The world first self-healing asphalt pavement using microcapsules containing rejuvenator, www.tjsinogo.cn (accessed: 2017).

[26] L. Francken, Transp. Res. Rec. 1979, 712, 30.

[27] M. Castro, J. A. Sánchez, Transp. Eng. J. ASCE 2006, 132, 168.

[28] D. N. Little, A. Bhasin, in Self Healing Materials, Springer, Dordrecht 2007, pp. 205-218.

[29] S. I. Sarsam, Int. J. Sci. Res. Knowl. 2015, 3, 001.

[30] T. P. Grant, Master Thesis, University of Florida, USA, 2001.

[31] Á. García, E. Schlangen, M. van de Ven, Q. Liu, Constr. Build. Mater. 2009, 23, 3175

[32] Á. García, E. Schlangen, M. van de Ven, D. van Vliet, Mater. Struct. 2011, 44, 499.

[33] X. Yang, Q. Dai, Z. You, Z. Wang, J. Mater. Civ. Eng. 2014, 27, 04014259.

[34] Á. García, Fuel 2012, 93, 264.

[35] J. Tang, Q. Liu, S. Wu, Q. Ye, Y. Sun, E. Schlangen, Constr. Build. Mater. 2016, 113, 1029.

[36] S. I. Sarsam, S. A. Barakhas, Int. J. Mater. Chem. Phys. 2015, 1, 399.

[37] Q. Liu, W. Yu, S. Wu, E. Schlangen, P. Pan, Constr. Build. Mater. 2017, 144, 663

[38] Q. Liu, B. Li, E. Schlangen, Y. Sun, S. Wu, Appl. Sci. 2017, 7, 1088.

[39] Q. Liu, E. Schlangen, M. van de Ven, G. van Bochove, J. van Montfort, Constr. Build. Mater. 2012, 29, 403.

[40] Y. Sun, S. Wu, Q. Liu, W. Zeng, Z. Chen, Q. Ye, P. Pan, Constr. Build. Mater. 2017, 150, 673 .

[41] B. Gómez-Meijide, H. Ajam, P. Lastra-González, A. Garcia, Constr. Build. Mater. 2016, 126, 957.

[42] H. M. R. D. Silva, J. R. M. Oliveira, C. M. G. Jesus, Resour., Conserv. Recycl. 2012, 60, 38.

[43] J. Brownridge, presented at 1st Int. Conf. Pavement Preservation, Newport Beach, USA, April 2010.

[44] A. G. Tabaković, A. C. McNally, M. D. Gilchrist, J. Mater. Civ. Eng. 2010, 22, 643.

[45] A. Tabaković, in Handbook of Recycled Concrete and Demolition Waste (Eds: F. Pacheco-Torgal, V. W. Y. Tam, J. A. Labrincha, Y. Ding, J. de Brito,), Woodhead Publishing, Cambridge 2013, pp. 394-419.

[46] A. Garcia, J. Jelfs, C. J. Austin, Constr. Build. Mater. 2015, 101, 8.
[47] J. F. Su, J. Qiu, E. Schlangen, Y. Y. Wang, Constr. Build. Mater. 2015, $74,83$.

[48] W. Steyn, Transp. Eng. J. ASCE 2009, 135, 764.

[49] J. Shen, S. Amirkhanian, J. A. Miller, J. Mater. Civ. Eng. 2007, 19, 376.

[50] J. F. Su, E. Schlangen, Chem. Eng. J. 2012, 198-199, 289.

[51] Á. García, E. Schlangen, M. van de Ven, Key Eng. Mater. 2010, 417418, 573.

[52] A. Tabaković, D. Braak, M. van Gerwen, O. Copuroglu, W. Post, S. J. Garcia, E. Schlangen, J. Traffic Transp. Eng. 2017, 4, 347.

[53] J.-F. Su, J. Qiu, E. Schlangen, Y.-Y. Wang, Mater. Struct. 2015, 48, 4067.

[54] A. Garcia, C. J. Austin, J. Jelfs, J. Cleaner Prod. 2016, 118, 9.

[55] J. Qiu, M. F. C. Van de Ven, S. Wu, J. Yu, A. A. A. Molenaar, in Proc. ICAM 2009, Vol. 10, Taylor \& Francis Group, China 2009, p. 81.

[56] D. Sun, J. Hu, X. Zhu, Colloid Polym. Sci. 2015, 293, 3505.

[57] A. Gibney, PhD Thesis, University College, Dublin, 2002.

[58] A. Gibney, in 3rd Eurasphalt \& Eurobitume Congress, Foundation Eurasphalt, Vienna, Austria 2004, pp. 1645-1651.

[59] J.-F. Su, J. Qiu, E. Schlangen, Y.-Y. Wang, Constr. Build. Mater. 2015, $74,83$.

[60] J.-F. Su, S. Han, Y.-Y. Wang, E. Schlangen, N.-X. Han, B. Liu, X.-L. Zhang, P. Yang, W. Li, Constr. Build. Mater. 2017, 147, 533.

[61] J.-F. Su, E. Schlangen, Chem. Eng. J. 2012, 198, 289.

[62] Y.-Y. Wang, J.-F. Su, E. Schlangen, N.-X. Han, S. Han, W. Li, Constr. Build. Mater. 2016, 121, 471.

[63] S. B. Jagtap, M. S. Mohan, P. G. Shukla, Polymer 2016, 83, 27

[64] J.-F. Su, Y.-Y. Wang, N.-X. Han, P. Yang, S. Han, Constr. Build. Mater. 2016, 106, 317.

[65] F. A. Anderson, J. Am. Coll. Toxicol. 1995, 14, 373.

[66] J. Zlopasa, E. A. B. Koenders, S. J. Picken, presented at 1st Int. Conf. Ageing of Materials a Structures, AMS 14, Delft, The Netherlands, May 2014.

[67] H. Grasdalen, B. Larsen, O. Smisrod, Carbohydr. Res. 1981, 89, 12.

[68] A. Linker, R. S. Jones, J. Biol. Chem. 1966, 241, 6.

[69] K. I. Draget, G. Skjåk-Bræk, O. Smidsrød, Int. J. Biol. Macromol. 1997, 21, 47.

[70] P. Laurienzo, Mar. Drugs 2010, 8, 30.

[71] B. Balakrishnana, M. Mohantyb, P. R. Umashankarc, A. Jayakrishnana, Biomaterials 2005, 26, 8.

[72] I. R. Matthew, R. M. Browne, J. W. Frame, B. G. Millar, Biomaterials $1995,16,4$

[73] D. Palin, V. Wiktor, H. M. Jonkers, presented at 5th Int. Conf. SelfHealing Materials, Durham, North Carolina, USA, June 2015.

[74] M. Prajer, X. Wu, S. J. Garcia, S. van der Zwaag, Compos. Sci. Technol. 2015, 106, 7.

[75] S. D. Mookhoek, H. R. Fischer, S. van der Zwaag, Composites, Part A 2012, 43, 7

[76] S. Van der Zwaag, A. Grande, W. Post, S. Garcia, T. C. Bor, Mater. Sci. Technol. 2014, 30, 1633.

[77] F. Gu, B. Amsden, R. Neufeld, J. Controlled Release 2004, 96, 463.

[78] S. Xu, A. Tabaković, E. Schlangen, X. Liu, in 6th Int. Conf. SelfHealing Materials, Friedrichshafen, Germany, 2017.

[79] E. R. Brown, P. S. Kandhal, J. Zhang, National Center for Asphalt Technology Report 2001

[80] B. Xue, H. Wang, J. Pei, R. Li, J. Zhang, Z. Fan, Constr. Build. Mater. 2017, 135, 641

[81] D. Sun, J. Hu, X. Zhu, Colloid Polym. Sci. 2015, 293, 12.

[82] A. Tabaković, E. Schlangen, in Self-Healing Materials, Springer, Switzerland 2015, pp. 285-306.

[83] A. Tabaković, L. Schuyffel, A. Karač, E. Schlangen, Appl. Sci. 2017, 7, 16.

[84] H. Fisher, Nat. Sci. 2010, 2, 873

[85] A. García, E. Schlangen, M. van de Ven, G. Sierra-Beltrán, J. Hazard Mater. 2010, 184, 9 